\title{
Reference Rock Site Condition for Central and Eastern North America
}

\author{
by Youssef M. A. Hashash, Albert R. Kottke, Jonathan P. Stewart, Kenneth W. Campbell, \\ Byungmin Kim, Cheryl Moss, Sissy Nikolaou, Ellen M. Rathje, and Walter J. Silva
}

\begin{abstract}
The reference rock site condition has two important applications for ground-motion prediction in the stable continental region of central and eastern North America (CENA). (1) It represents the site condition for which ground motions are computed using semiempirical ground-motion prediction equations. In addition, (2) it represents the site condition to which site amplification factors, which are used to modify ground-motion intensity measures for softer site condition, are referenced (i.e., site amplification is unity for reference rock). We define reference rock by its shear $(S)$ and compression $(P)$-wave velocities, as well as a site attenuation parameter $\left(\kappa_{0}\right)$, which is used in stochastic ground-motion simulation methods. Prior definitions of reference rock conditions in CENA were based mostly on indirect large-scale crustal velocity inversions and judgment. We compile and interpret a unique database of direct velocity measurements to develop criteria for assessing the presence of reference rock site condition based on measured seismic velocities and their gradient with respect to depth. We apply the criteria to available profiles and perform rigorous statistical analysis from which we recommend $S$ - and $P$-wave velocities of 3000 and $5500 \mathrm{~m} / \mathrm{s}$, respectively, for the reference rock condition. We recommend that, for practical applications, use ranges of reference $S$ - and $P$-wave velocities of $2700-3300 \mathrm{~m} / \mathrm{s}$ and $5000-6100 \mathrm{~m} / \mathrm{s}$, respectively. The ranges are based on a $\pm 5 \%$ change in amplification using quarterwavelength theory. We do not find evidence for regional dependence of the reference velocities, which are derived principally from three general geographic regions: (1) Atlantic coast, (2) continental interior, and (3) Appalachian Mountains. Our data do not provide reference velocities for the Gulf Coast region. The recommended velocity-compatible reference rock site kappa is $0.006 \mathrm{~s}$.
\end{abstract}

\section{Introduction}

Site amplification represents the altering of ground motions for a particular site condition relative to a reference condition, hereby referred to as the reference rock site condition. The reference rock site condition is defined by an $S$-wave velocity $\left(V_{S \text {,ref }}\right), P$-wave velocity $\left(V_{P, \text { ref }}\right)$, and site attenuation parameter $\left(\kappa_{0, \text { ref }}\right.$; used in stochastic groundmotion simulations, e.g., Anderson and Hough, 1984; Boore, 2003). There are significant differences in the reference rock site condition between active crustal regions, such as western North America (WNA), and stable continental regions, such as central and eastern North America (CENA; Boore and Joyner, 1997).

As part of the Next Generation Attenuation Relationships for CENA (NGA-East) Project, we have compiled a database of measured $P$ - and $S$-wave velocity profiles primarily from license applications from nuclear power plants and few from the published literature. We developed criteria for assessing the presence of reference rock site conditions based on trends observed in the database. The criteria were then used to select reference rock velocities $\left(V_{S \text {,ref }}\right.$ and $\left.V_{P, \text { ref }}\right)$ from profiles that are representative of the reference rock site condition and to define transition zones of weathered rock overlying reference rock. Prior work by the Electrical Power Research Institute (EPRI, 1993) defined reference rock based mostly on indirect large-scale crustal velocity inversions and judgment. The present paper is original both because of the quality of the data used to define reference rock and the method and transparency of the data interpretation.

Our work was performed within the framework of a Senior Seismic Hazard Analysis Committee (SSHAC) Level 3 process (Budnitz et al., 1997; Kammerer and Ake, 2012), during which we have evaluated whether the reference hardrock site condition in CENA should be revised from that provided by EPRI (1993).

This study focuses primarily on reference rock velocities systematically evaluated from compiled measurements. For completeness, we also summarize the selection of the reference velocity-compatible site attenuation parameter $\left(\kappa_{0, \text { ref }}\right)$ through a comprehensive compilation, review, and assessment of previous studies. 


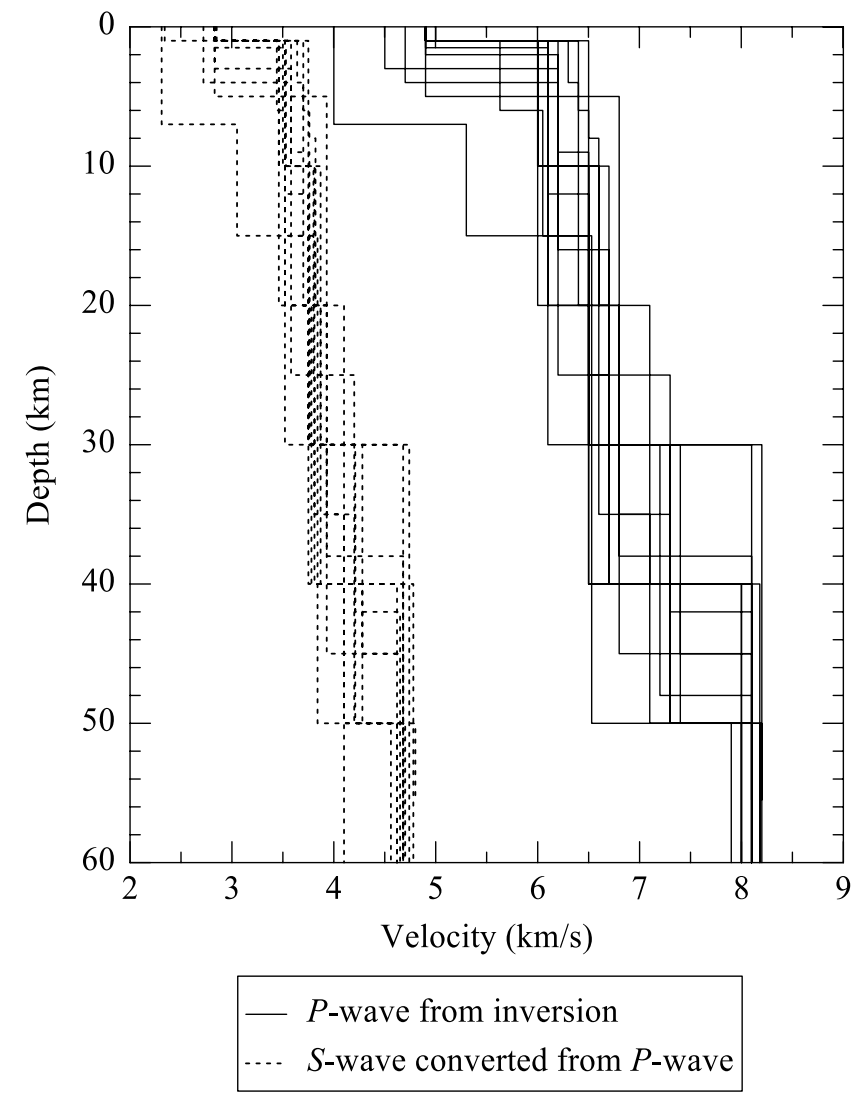

Figure 1. Summary of velocity models for the 16 regions in the EPRI (1993) study. $P$-wave velocities were estimated from inversions, and $S$-wave velocities were computed from $P$-wave velocities using an assumed Poisson's ratio of 0.25 .

\section{Prior Recommendation on Reference Rock}

The EPRI (1993) report established the current state-ofpractice for defining ground motions in the CENA region for nuclear facilities. The report identified 16 crustal structure regions within CENA as shown in Figure 1, which were developed using $P$-wave inversions. Using an assumed Poisson's ratio of $0.25, V_{S}$ was estimated from $V_{P}$. The crustal models extend to a depth of $55 \mathrm{~km}$. The crustal models are defined using intervals that increase in thickness with depth, but even the shallowest intervals near the surface are very thick $(1-5 \mathrm{~km})$. The estimated $V_{S}$ of the surface layer ranges from 2.31 to $2.83 \mathrm{~km} / \mathrm{s}$ with a value of $2.83 \mathrm{~km} / \mathrm{s}$ for 12 of 16 profiles. Several aspects of these models are important to recognize for the significance of the work presented in this paper to be placed in context. (1) The definition of the velocity structure is very coarse (on the order of kilometers). (2) The $P$-wave velocities were not directly measured, and (3) $S$-wave velocities were computed from $P$-wave velocities using an assumed Poisson's ratio.

Results of ground-motion simulations showed small differences among 15 of the 16 crustal models for the $2.31-2.83 \mathrm{~km} / \mathrm{s}$ range of surface layer $V_{S}$ (the exception was the Gulf Coast Plain). Accordingly, the 15 models producing
Table 1

Reference $S$-Wave Velocities Used by CENA GroundMotion Prediction Equations

\begin{tabular}{lc}
\hline \multicolumn{1}{c}{ Reference } & $V_{S, \text { ref }}(\mathrm{km} / \mathrm{s})$ \\
\hline Atkinson and Boore (2006) & $\geq 2.00$ \\
Campbell (2003) & 2.80 \\
Toro et al. $(1997)^{*}$ & 2.83 \\
Pezeshk et al. (2011) & $\geq 2.00$ \\
\hline
\end{tabular}

*Midcontinent region.

similar motions were combined into a single profile having a surface layer velocity of $V_{S, \text { ref }}=2.83 \mathrm{~km} / \mathrm{s}$ (EPRI, 1993). This combined region was referred to as the Midcontinent region in subsequent studies. Toro et al. (1997) developed ground-motion prediction equations (GMPEs) for these two regions (Midcontinent and Gulf Coast).

The EPRI (1993) study reported a median $\kappa_{0}$ of $0.006 \mathrm{~s}$. Initially, EPRI (1993) used a lognormal distribution to define $\kappa_{0}$ and proposed a natural $\log$ standard deviation of 0.40 to define the uncertainty associated with this parameter. However, EPRI (1993) eventually used three equally weighted values $(0.003,0.006$, and $0.012 \mathrm{~s})$ to define the total uncertainty in $\kappa_{0}$ in the development of a GMPE using a point-source stochastic simulation method (EPRI, 1993; Toro et al., 1997).

The U.S. Nuclear Regulatory Commission (NRC) provides the following guidance on the selection of $V_{S \text {,ref }}$ in NUREG-1.208 (NRC, 2007):

The hazard curves from the PSHA are defined for general surficial rock conditions that are consistent with the definition of rock for the attenuation relationships used in the PSHA. For example, existing attenuation relationships for the CEUS typically define generic rock conditions as materials with a shear wave velocity $\left(V_{S}\right)$ of $2.83 \mathrm{~km} / \mathrm{s}(9,200 \mathrm{ft} / \mathrm{s})$.

The recommendation of $2.83 \mathrm{~km} / \mathrm{s} \quad(9200 \mathrm{ft} / \mathrm{s})$ in NUREG-1.208 was adopted by the NRC to maintain compatibility with contemporaneous GMPEs used in the nuclear industry (e.g., Toro et al., 1997), which are based on the estimated $V_{S \text {,ref }}$ values from EPRI (1993). Table 1 shows reference site condition ranging from 2.00 to $2.88 \mathrm{~km} / \mathrm{s}$ for a number of GMPEs applicable to the CENA region (Toro et al., 1997; Campbell, 2003; Atkinson and Boore, 2006; Pezeshk et al., 2011). Those models are based on simulations, and hence the reference velocities reflect conditions at the top of assumed crustal profiles used in the simulations. It is important to recognize that the divergence in reference site conditions in GMPEs does not reflect varying interpretations of available profiles derived from data.

Since the EPRI (1993) work, no systematic data compilation and evaluation has been undertaken to support a defensible definition of reference rock. The work described in this study is meant to fill this need using prescribed protocols applied to high-quality data in a transparent, reviewable manner. 


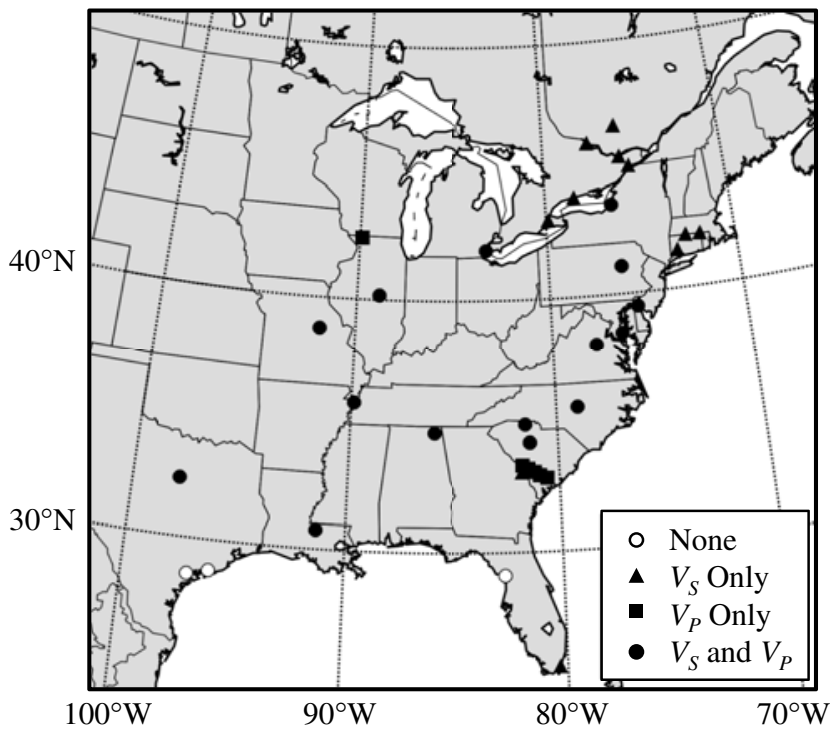

Figure 2. Locations of the reference $S$ - and $P$-wave velocity measurements.

\section{Reference $S$ - and $P$-Wave Velocity}

\section{Data Collection}

In this paper, $S$ - and $P$-wave velocity profiles that penetrate intact hard rock were collected from unpublished Nuclear Power Plant (NPP) license applications (U.S. Nuclear Regulatory Commission, 2013) at CENA sites and some published reports. These sources are contained in Dames \& Moore (1974), Daniels et al. (1983), Moos and Zoback (1983), Kafka and Skehan (1990), Dorman and Smalley (1994), Luetgert et al. (1994), Beresnev and Atkinson (1997), and Motazedian et al. (2011). Full citations of references from license applications that were considered are given in a published report (Hashash et al., 2013). Figure 2 shows the locations of sites with reference velocities. The collected velocity dataset does not uniformly sample the spatial distribution of the study region due to limitations in the available data. However, the data include a range of different geologic conditions so lack of spatial coverage may not be significant. Future efforts can be focused on acquiring additional data to ensure greater spatial coverage.

These data were screened for quality and then analyzed, to develop criteria to identify the CENA reference rock site condition. Data from both Midcontinent and Gulf Coast regions are included in this compilation. Two datasets were excluded:

1. A report by Dames \& Moore (1974) provides geology, $V_{S}$, and $V_{P}$ profiles at 61 nuclear power plants across the CENA region. The major concern with inclusion of this dataset was the poor quality of measurements and the inability to clearly identify assumptions that were made in development of the profiles.

2. The Motazedian et al. (2011) dataset is from a microzonation study for a portion of Ottawa, Canada. The dataset consists of refraction profiles at 531 sites with 508 measurements of the bedrock $V_{S}$ ranging from 940 to $6124 \mathrm{~m} / \mathrm{s}$. Motazedian et al. (2011) screened the data by removing outliers using the Grubbs' (Grubbs, 1969) and Chavenet's (Worthing and Geffner, 1943) rejection criteria. The resulting data ranged from 940 to $4895 \mathrm{~m} / \mathrm{s}$ with a mean of $2700 \mathrm{~m} / \mathrm{s}$, a standard deviation of $680 \mathrm{~m} / \mathrm{s}$, and coefficient of variation $(\mathrm{COV})=0.25$. H. Crow (personal comm., 2011) has suggested that high-velocity values resulted from uneven stratigraphic surfaces at the sites. With or without outlier removal, the range of the reported velocities is considered unrealistic. Moreover, there is significant uncertainty regarding whether the penetration depth of the refraction surveys is sufficiently large enough that the underlying intact rock is sampled. Accordingly, this dataset was not utilized.

\section{Definition of Reference Velocity}

We found that velocity profiles from the CENA region having a sufficiently large sampling depth to penetrate intact bedrock show some common characteristics. For example, as illustrated in Figure 3 from Bell Bend NPP, $S$ - and $P$-wave velocities increase with depth as the materials transition from soils into weathered rock and eventually intact rock. A striking feature of profiles from a significant majority of the available sites is the lack of increase with depth of shear-wave velocity within firm materials encountered near the bases of profiles. Defining the reference rock site condition on the basis of written descriptions from boring logs is not sufficient, because highly variable conditions in the rock $V_{S}$ profile can be present even for materials logged as intact rock. This results in part from the wide range of rock types sampled in our dataset. Instead, inspection of the velocity profiles revealed key features that are commonly encountered, and are used as criteria to define reference rock as follows:

1. We require $V_{S}>2000 \mathrm{~m} / \mathrm{s}$ and $V_{P}>3500 \mathrm{~m} / \mathrm{s}$ for a layer potentially defined as reference rock.

2. Reference rock layers must be sampled over a sufficiently large depth range so that velocity gradients, and potential weathered zones, can be identified. For the case of velocity profiles based on depth-controlled geophysical measurements (i.e., test types in which the geophysical receivers are located at depth; for example, suspension logging, crosshole, and downhole), logs must penetrate at least $10 \mathrm{~m}$ into a layer being considered as a reference rock material. For velocity profiles derived using geophysical methods without depth control (e.g., reflection or refraction surveys, surface-wave methods), no such penetration criteria are used. Profiles developed from surface-wave methods are only considered if the layers judged to have reference velocity are not the first layer in the profile below shallower materials having relatively slow velocities and relatively steep velocity gradients.

3. The velocity gradient with respect to depth $(d V / d z)$ is negligible to small within the reference rock. Typically, 

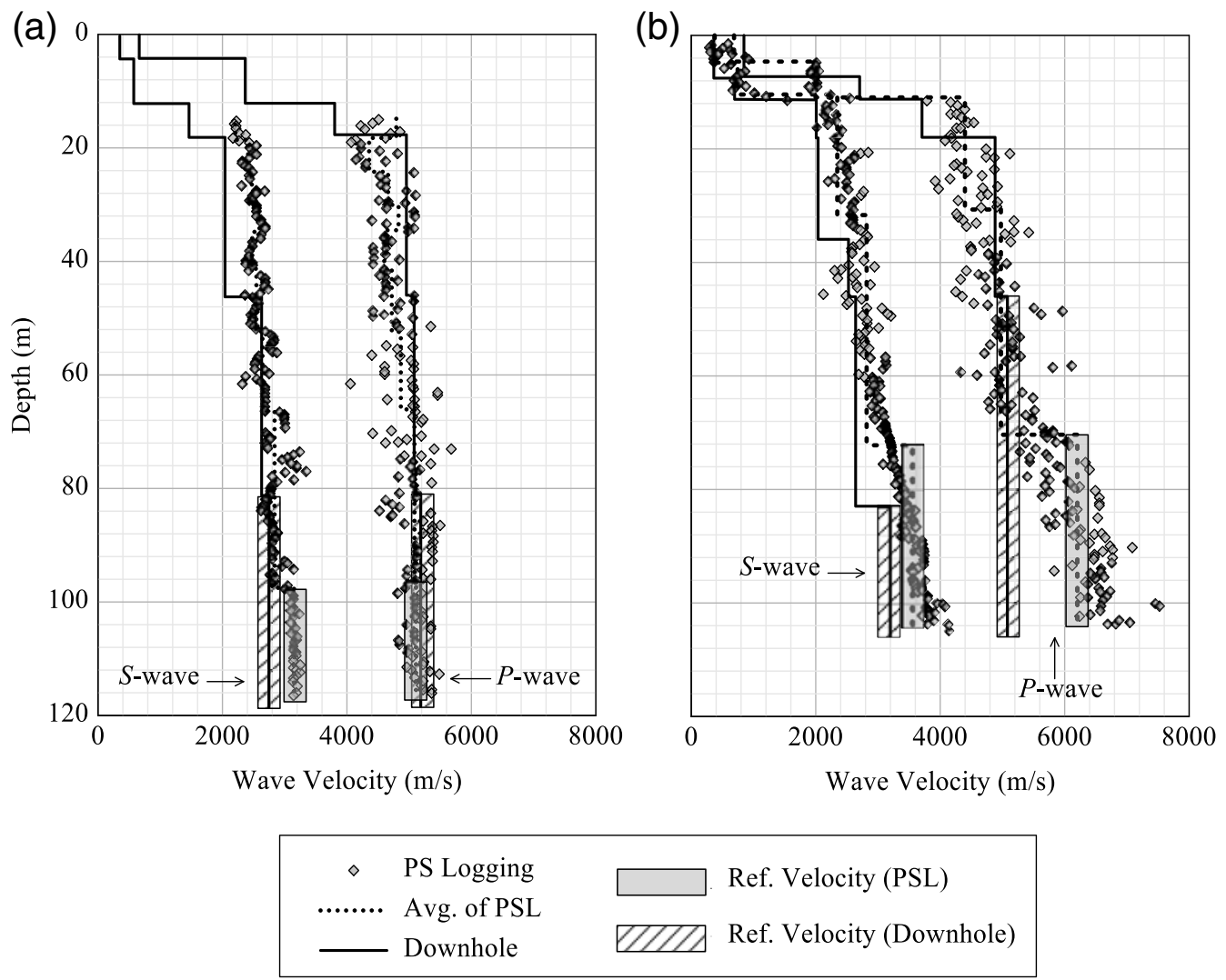

Figure 3. Wave velocities measured using $P$ - and $S$-wave suspension logging (PSL) and downhole methods at Bell Bend NPP from (a) figure 2.5-151 and (b) figure 2.5-152 in UniStar Nuclear Services LLC (2010).

this condition is achieved over depth intervals at least 5-10 $\mathrm{m}$ in thickness and associated gradients are generally less than $25(\mathrm{~m} / \mathrm{s}) / \mathrm{m}$. More information on this criterion is provided later in this paper.

4. Reference rock units should be from the materials of Paleozoic and older (>251 Myr) age, although this criterion is not used in cases in which age is unknown.

For each site satisfying the above criteria, a mean profile velocity, $\left(\bar{V}_{S, \text { ref }}\right)_{\text {pr }}$, was evaluated within the reference rock layer, as illustrated for example in Figure 3.

\section{Evaluation of Reference Velocity}

The total number of profiles examined in this work was 283 , of which 128 satisfied the reference rock velocity conditions. These 128 profiles were digitized and the mean reference rock velocity was computed over the interpreted depth range. This process yielded $68 S$-wave velocities at 27 different locations and $60 P$-wave velocities at 22 different locations, which are listed in Table 2.

Chulick and Mooney (2002), later updated by W. D. Mooney (personal comm., 2012), define crustal properties within four general regions of the CENA: (1) continental interior, (2) Gulf Coast, (3) Appalachian Mountains, and (4) Atlantic coast. All but one of the sites with reference rock velocities are located within the continental interior (13 sites),
Atlantic coast region (17 sites), or Appalachian Mountains (2 sites). We have relatively limited coverage along the Gulf Coast region. These regional designations are indicated for each site in Table 2. The velocity profiles from three Gulf Coast nuclear plants (Levy County, South Texas, and Victoria County) were not sufficiently deep to sample the reference rock condition despite measurements to depths of 1400-4000 m.

Of the $68 S$-wave profiles, 58 are from direct measurements of the in situ $S$-wave velocity. The remaining 10 values have estimated $V_{S}$ using measured $V_{P}$ and an assumed Poisson's ratio as listed in Table 2. Figures 4 and 5 present box plots of the reference $S$ - and $P$-wave velocities, respectively, at the various sites showing the range of data. The selected $S$ - and $P$-wave reference velocities show no discernable trend with depth as shown in Figure 6.

The data collected in this study provide information on the aleatory uncertainty at three different scales: profile, site, and region. At each of these scales, the data are used to quantify the expected value and uncertainty, as well as to test statistical distributions.

Within-Profile Characteristics. At the profile level, the reference rock depth range is identified and used to select individual within-profile measurements of reference rock velocities $\left(V_{S \text {,ref }}\right.$ and $\left.V_{P, \text { ref }}\right)$. The Shapiro-Wilk test (Shapiro and Wilk, 1965) was used to test if the distribution of 
Table 2

Reference $S$ - and $P$-Wave Velocities for All Profiles

\begin{tabular}{|c|c|c|c|c|c|c|c|c|c|}
\hline Site & $\begin{array}{l}\text { Latitude } \\
\left({ }^{\circ} \mathrm{N}\right)\end{array}$ & $\begin{array}{l}\text { Longitude } \\
\left({ }^{\circ} \mathrm{E}\right)\end{array}$ & $\begin{array}{l}V_{P, \text { ref }} \\
(\mathrm{m} / \mathrm{s})\end{array}$ & $\begin{array}{l}\sigma_{V_{P, \text { pef }}}^{\mathrm{pr}} \\
(\mathrm{m} / \mathrm{s})\end{array}$ & $\begin{array}{l}V_{S, \text { ref }} \\
(\mathrm{m} / \mathrm{s})\end{array}$ & $\begin{array}{l}\sigma_{V_{\text {S.ef }}}^{\mathrm{pr}} \\
(\mathrm{m} / \mathrm{s})\end{array}$ & $\begin{array}{l}\text { Poisson's } \\
\text { Ratio }\end{array}$ & Method & Reference \\
\hline Bell Bend NPP*, ${ }^{\dagger}$ & 41.086 & -76.165 & 5186 & - & 2747 & - & - & Downhole & FSAR Figure $2.5-151^{\ddagger}$ \\
\hline Bell Bend NPP & 41.086 & -76.165 & 5102 & 151 & 3150 & 52 & - & $P S$ logging & FSAR Figure 2.5-151 \\
\hline Bell Bend NPP & 41.086 & -76.165 & 5080 & - & 3191 & - & - & Downhole & FSAR Figure $2.5-152$ \\
\hline Bell Bend NPP & 41.086 & -76.165 & 6203 & 456 & 3543 & 228 & - & $P S$ logging & FSAR Figure $2.5-152$ \\
\hline Bell Bend NPP & 41.086 & -76.165 & 4007 & - & 2340 & - & - & Downhole & FSAR Figure $2.5-153$ \\
\hline Bell Bend NPP & 41.086 & -76.165 & 4750 & 318 & 2762 & 142 & - & $P S$ logging & FSAR Figure $2.5-153$ \\
\hline Bell Bend NPP & 41.086 & -76.165 & 5552 & - & 2527 & - & - & Downhole & FSAR Figure $2.5-154$ \\
\hline Bell Bend NPP & 41.086 & -76.165 & 5186 & 415 & 3110 & 76 & - & $P S$ logging & FSAR Figure $2.5-154$ \\
\hline Bellefonte NPP* & 34.713 & -85.925 & 5910 & 356 & 2939 & 185 & - & $P S$ logging & FSAR Figure 2.5-331 \\
\hline Bellefonte NPP & 34.713 & -85.925 & 5686 & - & 2905 & - & - & Downhole & FSAR Figure $2.5-333$ \\
\hline Bellefonte NPP & 34.713 & -85.925 & 5806 & 337 & 2900 & 194 & - & $P S$ logging & FSAR Figure $2.5-333$ \\
\hline Bellefonte NPP & 34.713 & -85.925 & 5964 & 385 & 2973 & 209 & - & $P S$ logging & FSAR Figure 2.5-334 \\
\hline Bellefonte NPP & 34.713 & -85.925 & 5861 & 282 & 3036 & 223 & - & $P S$ logging & FSAR Figure $2.5-335$ \\
\hline Bellefonte NPP & 34.713 & -85.925 & 5870 & - & 2830 & - & - & Downhole & FSAR Figure 2.5-336 \\
\hline Bellefonte NPP & 34.713 & -85.925 & 5711 & 213 & 3109 & 86 & - & $P S$ logging & FSAR Figure $2.5-336$ \\
\hline Bellefonte NPP & 34.713 & -85.925 & 5958 & 252 & 3129 & 129 & - & $P S$ logging & FSAR Figure 2.5-337 \\
\hline Chalkn River, Ontario ${ }^{\S}$ & 45.990 & -77.450 & - & - & 3210 & - & - & Refraction & Beresnev and Atkinson (1997) \\
\hline $\begin{array}{l}\text { Grand Remous, } \\
\text { Ontario }\end{array}$ & 46.610 & -75.860 & - & - & 2850 & - & - & Refraction & Beresnev and Atkinson (1997) \\
\hline Ottawa, Ontario ${ }^{\S}$ & 45.390 & -75.720 & - & - & 2700 & - & - & Refraction & Beresnev and Atkinson (1997) \\
\hline Tyneside, Ontario ${ }^{\S}$ & 43.090 & -79.870 & - & - & 3380 & - & - & Refraction & Beresnev and Atkinson (1997) \\
\hline Williamsburg, Ontario ${ }^{\S}$ & 45.000 & -75.250 & - & - & 3110 & - & - & Refraction & Beresnev and Atkinson (1997) \\
\hline Wesleyville, Ontario ${ }^{\S}$ & 43.920 & -78.400 & - & - & 3030 & - & - & Refraction & Beresnev and Atkinson (1997) \\
\hline Callaway NPP ${ }^{\S}$ & 38.763 & -91.782 & 4350 & - & 2544 & - & - & Downhole & FSAR Figure 2.5.4-19 \\
\hline Callaway NPP & 38.763 & -91.782 & 4551 & 372 & 2482 & 181 & - & $P S$ logging & FSAR Figure 2.5.4-19 \\
\hline Calvert Cliffs" & 38.432 & -76.442 & 4118 & - & 2377 & 422 & 0.25 & $P$ logging & FSAR Figure $2.5-142$ \\
\hline Calvert Cliffs & 38.432 & -76.442 & 6203 & - & 3581 & 612 & 0.25 & $P$ logging & FSAR Figure $2.5-143$ \\
\hline Calvert Cliffs & 38.432 & -76.442 & 4223 & - & 2438 & - & 0.25 & $P$ logging & FSAR Figure $2.5-144$ \\
\hline Clinton NPP ${ }^{\S}$ & 40.172 & -88.835 & 4387 & - & 2533 & - & 0.25 & $P$ logging & ESP, Figure $4.2-8^{\#}$ \\
\hline Comanche Peak NPP§ & 32.302 & -97.793 & 6212 & - & 3324 & - & 0.3 & $P$ logging & FSAR Table 2.5.2-227 \\
\hline Daniels et al., UPH3 ${ }^{\S}$ & 42.438 & -89.871 & 6090 & 389 & - & - & - & $P$ logging & Daniels et al. (1983) \\
\hline Hayes $^{\S}$ & 35.865 & -89.849 & 6100 & - & 3408 & - & 0.28 & $P$ logging & Dorman and Smalley (1994) \\
\hline Fermi NPP ${ }^{\S}$ & 41.962 & -83.260 & 5174 & 467 & 2838 & 195 & - & $P S$ logging & FSAR Figure 2.5.4-220 \\
\hline Fermi NPP & 41.962 & -83.260 & 4930 & - & - & - & - & Downhole & FSAR Figure 2.5.4-221 \\
\hline Fermi NPP & 41.962 & -83.260 & 5536 & 429 & 2934 & 199 & - & $P S$ logging & FSAR Figure 2.5.4-221 \\
\hline Bronson-Avalon" & 42.026 & -71.868 & - & - & 3024 & - & - & $\begin{array}{l}\text { Group } \\
\text { velocity }\end{array}$ & Kafka and Skehan (1990) \\
\hline Hartford" & 42.055 & -72.648 & - & - & 2712 & - & - & $\begin{array}{l}\text { Group } \\
\text { velocity }\end{array}$ & Kafka and Skehan (1990) \\
\hline Waterbury" & 41.485 & -73.158 & - & - & 3304 & - & - & $\begin{array}{l}\text { Group } \\
\text { velocity }\end{array}$ & Kafka and Skehan (1990) \\
\hline $\begin{array}{l}\text { Luetgert et al. (94), } \\
\text { SP1\| }\end{array}$ & 33.411 & -81.707 & 6100 & - & - & - & - & Reflection & Luetgert et al. (1994) \\
\hline Luetgert et al. (94), SP2 & 33.267 & -81.441 & 6100 & - & - & - & - & Reflection & Luetgert et al. (1994) \\
\hline Luetgert et al. (94), SP3 & 33.128 & -81.162 & 6200 & - & - & - & - & Reflection & Luetgert et al. (1994) \\
\hline Luetgert et al. (94), SP4 & 33.007 & -80.919 & 5730 & - & - & - & - & Reflection & Luetgert et al. (1994) \\
\hline Luetgert et al. (94), SP5 & 32.883 & -80.581 & 5730 & - & - & - & - & Reflection & Luetgert et al. (1994) \\
\hline Monticello Reservoir" & 34.320 & -81.334 & 6056 & 295 & 3361 & 180 & - & $P S$ logging & $\begin{array}{l}\text { Moos and Zoback (1983), } \\
\text { figure } 4\end{array}$ \\
\hline Monticello Reservoir & 34.320 & -81.334 & 6000 & 397 & 3333 & 276 & - & $P S$ logging & $\begin{array}{l}\text { Moos and Zoback (1983), } \\
\text { figure } 5\end{array}$ \\
\hline Monticello Reservoir & 34.320 & -81.334 & 5500 & 190 & 3200 & 135 & - & $P S$ logging & $\begin{array}{l}\text { Moos and Zoback (1983), } \\
\text { figure } 7\end{array}$ \\
\hline Nine Mile $\mathrm{NPP}^{\dagger}$ & 43.521 & -76.407 & 6231 & - & 3444 & - & - & $P S$ logging & FSAR Table 2.5-58 \\
\hline North Anna NPP" & 38.059 & -77.795 & 5258 & 398 & 2900 & 365 & - & $P S$ logging & ESP Geophysics Figure 5 \\
\hline North Anna NPP & 38.059 & -77.795 & 5635 & 316 & 3167 & 256 & - & $P S$ logging & ESP Geophysics Figure 8 \\
\hline PSEG NPP\| & 39.463 & -75.536 & - & - & 3353 & - & 0.3 & $P$ logging & ESP, Figure 2.5.4.7-15 \\
\hline PSEG NPP & 39.463 & -75.536 & 5800 & - & - & - & - & Refraction & ESP, Figure 2.5.4.7-14 \\
\hline PSEG NPP & 39.463 & -75.536 & 6670 & - & - & - & - & Refraction & ESP, Figure 2.5.4.7-14 \\
\hline
\end{tabular}


Table 2 (Continued)

\begin{tabular}{|c|c|c|c|c|c|c|c|c|c|}
\hline Site & $\begin{array}{l}\text { Latitude } \\
\left({ }^{\circ} \mathrm{N}\right)\end{array}$ & $\begin{array}{l}\text { Longitude } \\
\left({ }^{\circ} \mathrm{E}\right)\end{array}$ & $\begin{array}{l}V_{P, \text { ref }} \\
(\mathrm{m} / \mathrm{s})\end{array}$ & $\begin{array}{l}\sigma_{V_{V_{\text {, pef }}}}^{\mathrm{pr}} \\
(\mathrm{m} / \mathrm{s})\end{array}$ & $\begin{array}{l}V_{S, \text { ref }} \\
(\mathrm{m} / \mathrm{s})\end{array}$ & $\begin{array}{l}\sigma_{V_{S \text { Sef }}}^{\mathrm{pr}} \\
(\mathrm{m} / \mathrm{s})\end{array}$ & $\begin{array}{l}\text { Poisson's } \\
\text { Ratio }\end{array}$ & Method & Reference \\
\hline River Bend NPP** & 30.756 & -91.334 & 3658 & - & 2134 & 299 & 0.25 & $P$ logging & FSAR Figure 2.5.4-245 \\
\hline Shearon Harris NPP\| & 35.633 & -78.955 & 4548 & 309 & 2350 & 150 & 0.3 & $P$ logging & Figure $2.5 .2-262$ \\
\hline V.C. Summer NPP\| & 34.285 & -81.321 & 5428 & 89 & 3121 & 79 & - & $P S$ logging & $\begin{array}{l}\text { FSAR Figure 2.5.4-224/225, } \\
\text { В } P-201\end{array}$ \\
\hline V.C. Summer NPP & 34.285 & -81.321 & 5345 & 225 & 3023 & 191 & - & $P S$ logging & $\begin{array}{l}\text { FSAR Figure 2.5.4-224/225, } \\
\text { B } P-206\end{array}$ \\
\hline V.C. Summer NPP & 34.285 & -81.321 & 5281 & 180 & 3174 & 161 & - & $P S$ logging & $\begin{array}{l}\text { FSAR Figure 2.5.4-224/225, } \\
\text { B } P-207\end{array}$ \\
\hline V.C. Summer NPP & 34.285 & -81.321 & 5871 & 267 & 3124 & 200 & - & $P S$ logging & $\begin{array}{l}\text { FSAR Figure 2.5.4-224/225, } \\
\text { В } P-211\end{array}$ \\
\hline V.C. Summer NPP & 34.285 & -81.321 & 5475 & 290 & 3249 & 185 & - & $P S$ logging & $\begin{array}{l}\text { FSAR Figure 2.5.4-224/225, } \\
\text { B } P-301\end{array}$ \\
\hline V.C. Summer NPP & 34.285 & -81.321 & 5397 & 182 & 3134 & 133 & - & $P S$ logging & $\begin{array}{l}\text { FSAR Figure 2.5.4-224/225, } \\
\text { B } P-306\end{array}$ \\
\hline V.C. Summer NPP & 34.285 & -81.321 & 5581 & 136 & 3447 & 76 & - & $P S$ logging & $\begin{array}{l}\text { FSAR Figure 2.5.4-224/225, } \\
\text { B } P-307\end{array}$ \\
\hline V.C. Summer NPP & 34.285 & -81.321 & 5939 & 227 & 3220 & 168 & - & $P S$ logging & $\begin{array}{l}\text { FSAR Figure 2.5.4-224/225, } \\
\text { B } P-311\end{array}$ \\
\hline Turkey Point NPP\| & 25.424 & -80.333 & - & - & 2903 & 100 & 0.3 & $P$ logging & FSAR Figure 2.5.4-211 \\
\hline Vogtle NPP\| & 33.141 & -81.763 & - & - & 2671 & 344 & - & $P S$ logging & FSAR Figure 2.5.4-8 \\
\hline Vogtle NPP & 33.141 & -81.763 & - & - & 2919 & 240 & - & $P S$ logging & FSAR Figure 2.5.4-8 \\
\hline Vogtle NPP & 33.141 & -81.763 & - & - & 2600 & 223 & - & $P S$ logging & FSAR Figure 2.5.4-8 \\
\hline $\begin{array}{l}\text { William States Lee III } \\
\text { NPP\| }\end{array}$ & 35.037 & -81.512 & - & - & 3397 & 287 & - & Downhole & FSAR Figure 2.5.4-219 \\
\hline $\begin{array}{l}\text { William States Lee III } \\
\text { NPP }\end{array}$ & 35.037 & -81.512 & 6749 & 280 & 3302 & - & - & $P S$ logging & FSAR Figure 2.5.4-219 \\
\hline $\begin{array}{l}\text { William States Lee III } \\
\text { NPP }\end{array}$ & 35.037 & -81.512 & 5746 & 504 & 3035 & 331 & - & $P S$ logging & FSAR Figure 2.5.4-220 \\
\hline $\begin{array}{l}\text { William States Lee III } \\
\text { NPP }\end{array}$ & 35.037 & -81.512 & 5888 & 531 & 2858 & 283 & - & $P S$ logging & FSAR Figure 2.5.4-221 \\
\hline $\begin{array}{l}\text { William States Lee III } \\
\text { NPP }\end{array}$ & 35.037 & -81.512 & - & - & 2762 & - & - & Downhole & FSAR Figure 2.5.4-222 \\
\hline $\begin{array}{l}\text { William States Lee III } \\
\text { NPP }\end{array}$ & 35.037 & -81.512 & 5292 & 333 & 2953 & 230 & - & $P S$ logging & FSAR Figure 2.5.4-222 \\
\hline $\begin{array}{l}\text { William States Lee III } \\
\text { NPP }\end{array}$ & 35.037 & -81.512 & 5627 & 413 & 2918 & 337 & - & $P S$ logging & FSAR Figure 2.5.4-223 \\
\hline $\begin{array}{l}\text { William States Lee III } \\
\text { NPP }\end{array}$ & 35.037 & -81.512 & 5607 & 342 & 2794 & 229 & - & $P S$ logging & FSAR Figure 2.5.4-224 \\
\hline $\begin{array}{l}\text { William States Lee III } \\
\text { NPP }\end{array}$ & 35.037 & -81.512 & 5528 & 445 & 2819 & 338 & - & $P S$ logging & FSAR Figure 2.5.4-225 \\
\hline $\begin{array}{l}\text { William States Lee III } \\
\text { NPP }\end{array}$ & 35.037 & -81.512 & - & - & 2794 & - & - & Downhole & FSAR Figure 2.5.4-226 \\
\hline $\begin{array}{l}\text { William States Lee III } \\
\text { NPP }\end{array}$ & 35.037 & -81.512 & 6096 & 401 & 3080 & 290 & - & $P S$ logging & FSAR Figure 2.5.4-226 \\
\hline $\begin{array}{l}\text { William States Lee III } \\
\text { NPP }\end{array}$ & 35.037 & -81.512 & 5497 & 335 & 2794 & 287 & - & $P S$ logging & FSAR Figure 2.5.4-232 \\
\hline
\end{tabular}

*Region: Appalachian Mountains

${ }^{\dagger}$ NPP, Nuclear Power Plant

FFSAR, Final Safety Analysis Report

${ }^{\S}$ Region: continental interior

"Region: Atlantic coast

\#ESP, Early Site Permit

**Region: Gulf Coast

within-profile measurements follows a normal or lognormal distribution. If the $p$ value from the test is lower than a chosen confidence level, typically $0.05-0.10$, then the null hypothesis that the data are from the assumed distribution can be rejected. Using a confidence level of 0.10 , the test was found to reject the normal and lognormal distributions for the majority of the $V_{S \text {,ref }}$ and $V_{P \text {,ref }}$ profiles, as shown in Figure 7. To better understand the distribution of withinprofile measurements, the $V_{S \text {,ref }}$ data are combined together after subtracting the within-profile mean values. This 


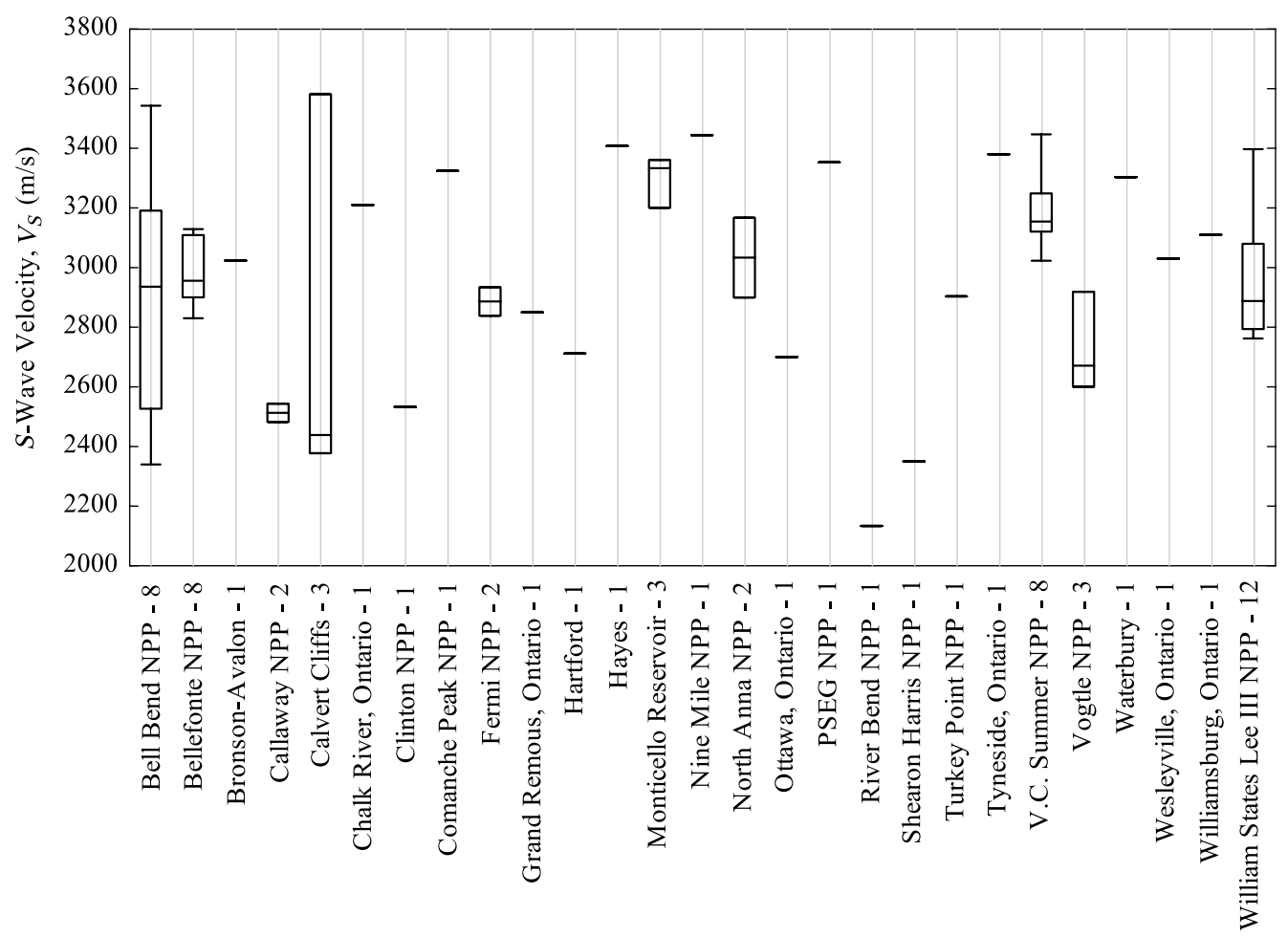

Figure 4. Reference $S$-wave velocity and number of values. Boxplot shows the minimum and maximum (outside bars), 25th and 75 th percentile (box), and the median (bar inside of box).

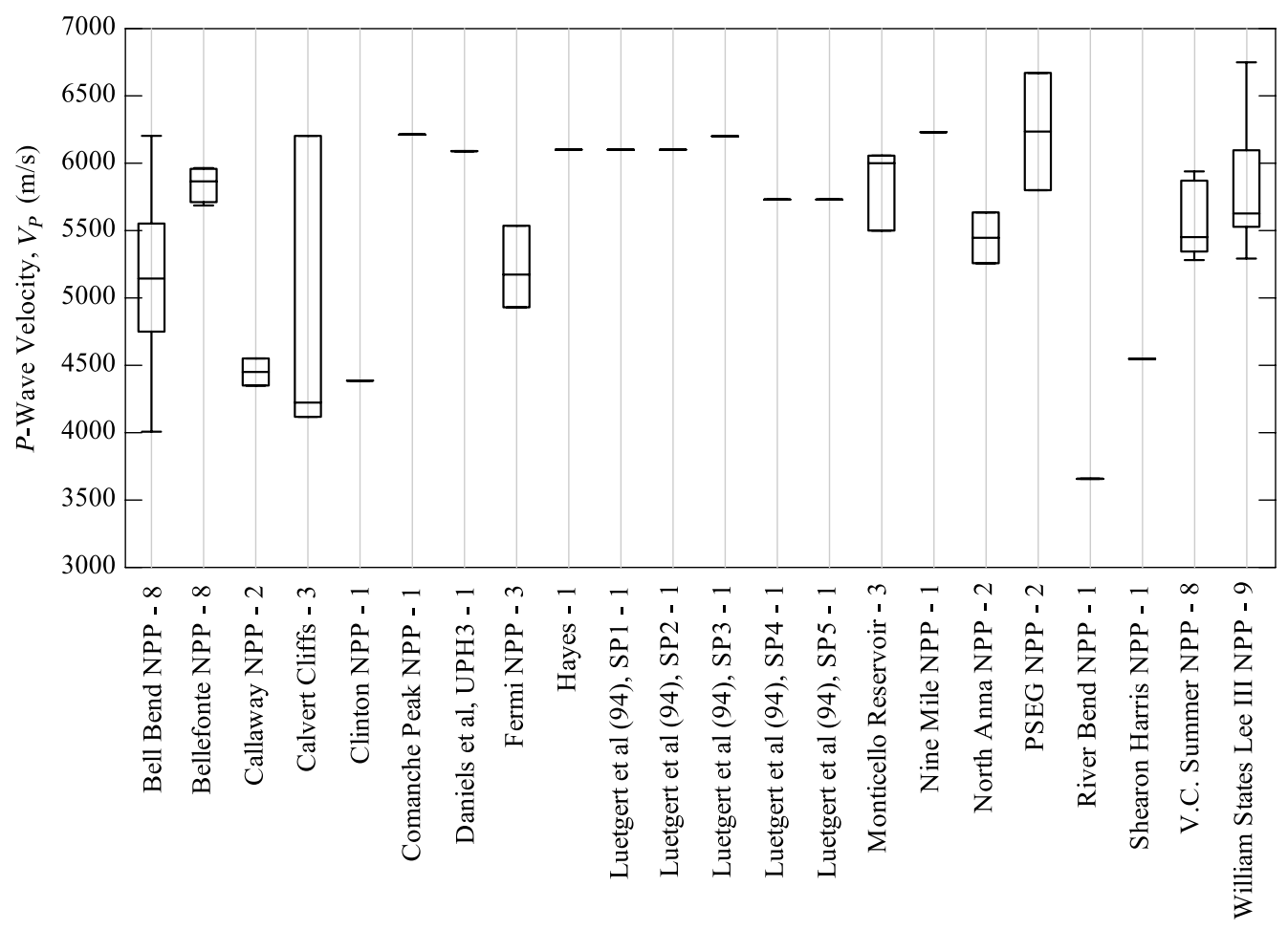

Figure 5. Reference $P$-wave velocity and number of values. See Figure 4 for boxplot description. 


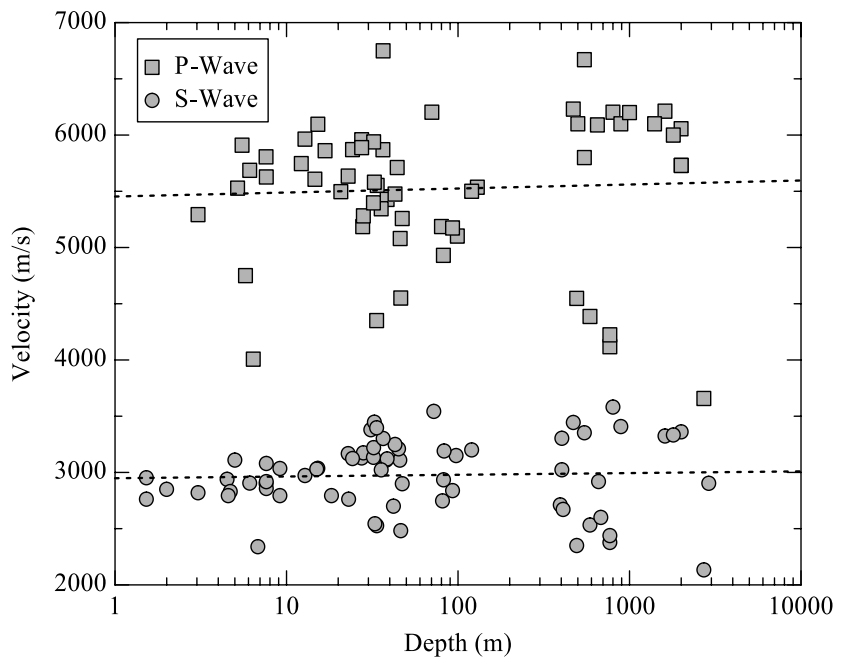

Figure 6. Influence of depth on the reference $P$ - and $S$-wave velocities with semilog-linear fits through the $S$ - and $P$-wave velocity data.

transformation is applied to original datasets under the assumption of a normal distribution with constant uncertainty, as well as to the natural log of the data under the assumption of a lognormal distribution. Figure 8 shows the test of the normal distribution, and indicates that the data are more strongly clustered at the center than expected from the theoretical distribution with the sample standard deviation. There are also differences at tails of the histogram (quantiles $<-3$ and $>+3$ ). The data have more than expected observations at the tails with several observations that differ by more than $\pm 1000 \mathrm{~m} / \mathrm{s}$ from the mean. Similar trends are observed for the lognormal distribution, shown in Figure 9. The Shapiro-Wilk test was used to test for normality and was found to reject both normal and lognormal distributions. The rejection by the Shapiro-Wilk test was due to longer than expected tails. A similar evaluation of the $V_{P, \text { ref }}$ data (see Figs. 10 and 11) shows that both of the assumed distributions fit the data better than the case for the $V_{S \text {,ref }}$ data.

Subsequent analysis of velocity statistics in this paper requires the selection of a distribution so that the proper form of the standard deviation is used (e.g., COV for normal, $\sigma_{\ln V}$ for log normal). Neither distribution is clearly preferred based on the Shapiro-Wilk tests, as described previously in this paper. Previous researchers have generally applied lognormal distributions to characterize soil velocity data (e.g., Roblee et al., 1996; Andrus et al., 2006). Nonetheless, a normal distribution is selected, principally because it is more representative of the within-site and within-region distributions considered subsequently.

Each of the profiles has a mean reference velocity, $\left(\bar{V}_{S, \text { ref }}\right)_{\mathrm{pr}}$ and $\left(\bar{V}_{P, \text { ref }}\right)_{\mathrm{pr}}$, and within-profile standard deviations, $\sigma_{V_{S} \text {,ref }}^{\mathrm{pr}}$ and $\sigma_{V_{P}, \text { ref }}^{\mathrm{pr}}$. These standard deviation terms, provided in Table 2, range from 52 to $612 \mathrm{~m} / \mathrm{s}$. There is a slight trend in within-profile standard deviation with mean profile velocity, shown in Figure 12, thus dispersion is represented with a COV instead of standard deviation. The within-profile COV range from 0.01 to 0.18 for $\mathrm{COV}_{V_{S} \text {, ref }}^{\mathrm{pr}}$ and from 0.02 to 0.09 for $\mathrm{COV}_{V_{P}, \text { ref }}^{\mathrm{pr}}$, shown in Figure 13. The average COV values for $S$ and $P$ waves (0.067) are used as an estimate of within-profile coefficient of variation $\left(\mathrm{COV}_{\text {profile }}\right)$.

Between-Profile Characteristics. The mean $S$-wave velocity at each of the profiles, provided in Table 2 and shown in Figure 4, ranges from $2134 \mathrm{~m} / \mathrm{s}$ at River Bend NPP located in Louisiana to $3581 \mathrm{~m} / \mathrm{s}$ at Calvert Cliffs NPP located in Maryland. For sites with multiple profiles, the mean can be taken across the datasets for the site as a whole, $\left(\bar{V}_{S \text {,ref }}\right)_{\text {site }}$ and $\left(\bar{V}_{P, \text { ref }}\right)_{\text {site }}$, and a between-profile standard deviation of reference velocity can be computed, $\sigma_{V_{S}}^{\text {site }}$,ef and $\sigma_{V_{P}}^{\text {site }}$, ef .

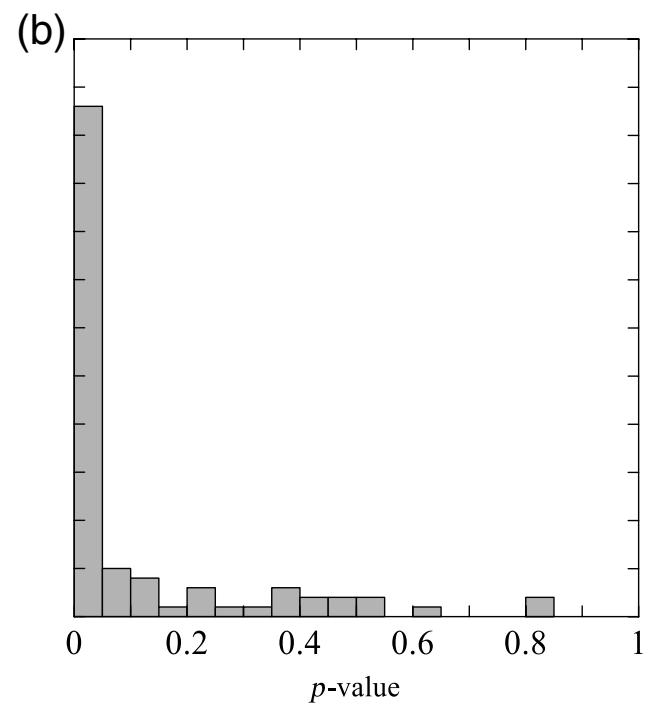

Figure 7. The $p$ value from Shapiro-Wilk tests on (a) normal and (b) lognormal distributions of within-profile measurements of the reference velocity. Typical thresholds for rejection of the assumed distribution are $<0.05$ or $<0.10$. 

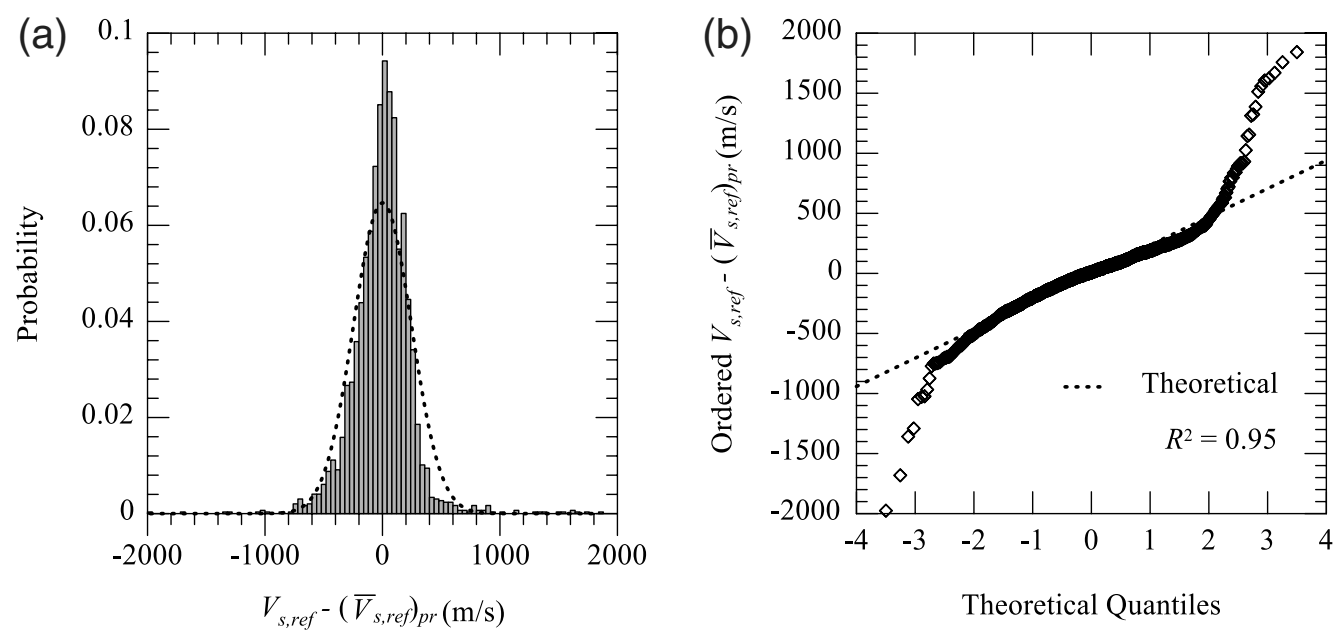

Figure 8. (a) Comparison of the within-profile $V_{S \text {,ref }}$ data to a normal distribution, (b) the ordered mean values versus theoretical quantiles (or $Q-Q$ plot) by comparing the shape of the distribution with the assumed normal distribution. Deviations from the 1-to-1 line indicate deviations from the assumed distribution.
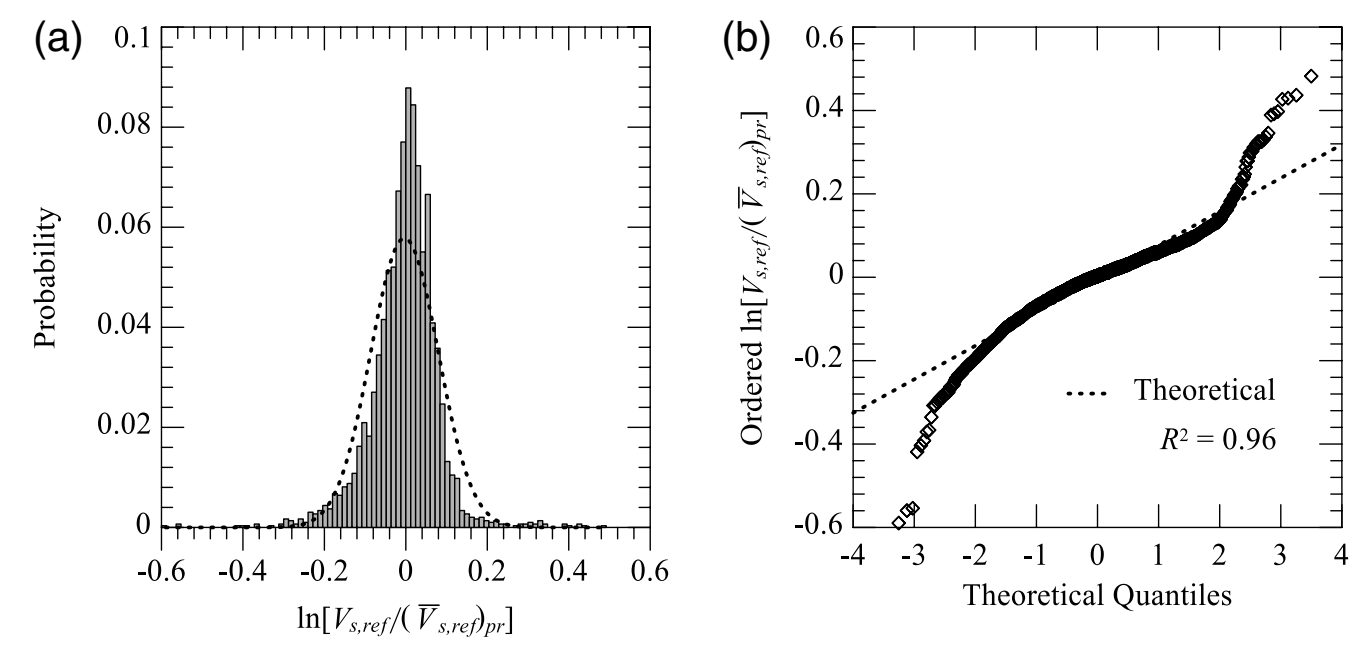

Figure 9. (a) Comparison of the within-profile $V_{S, \text { ref }}$ data to a lognormal distribution, (b) the ordered mean values versus theoretical quantiles (or $Q-Q$ plot). See Figure 8 for a description of the figure.
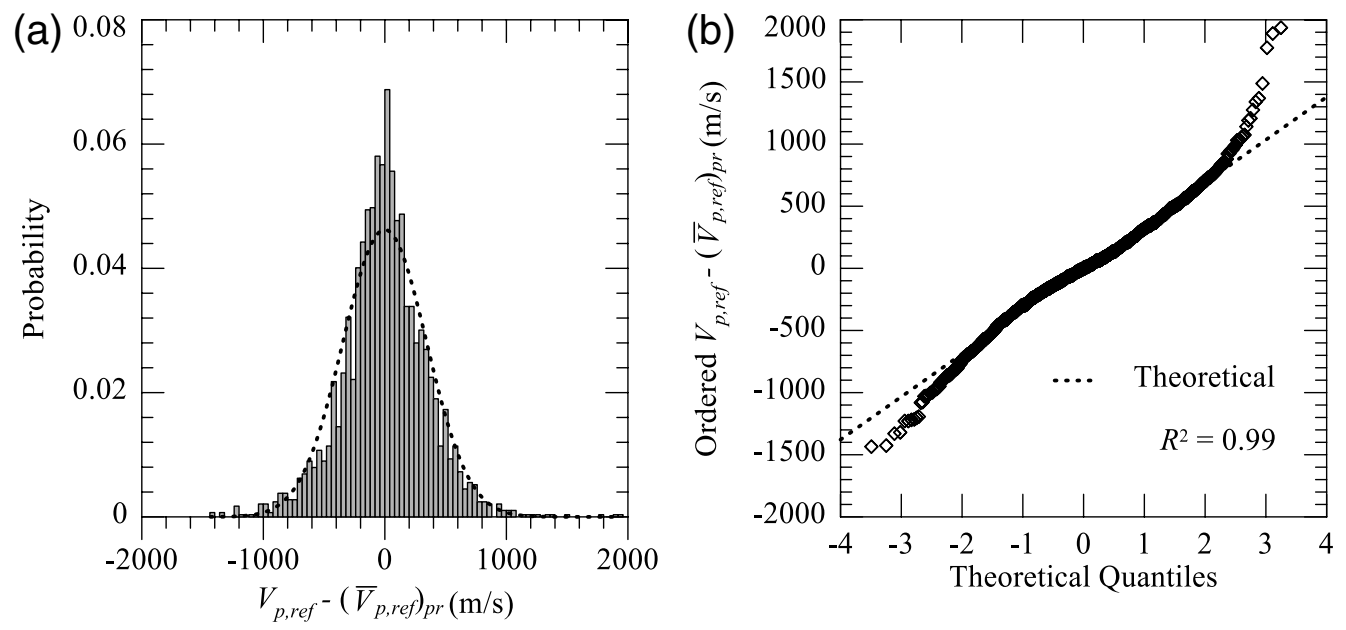

Figure 10. (a) Comparison of the within-profile $V_{P, \text { ref }}$ data to a normal distribution, (b) the ordered mean values versus theoretical quantiles (or $Q-Q$ plot). See Figure 8 for a description of the figure. 

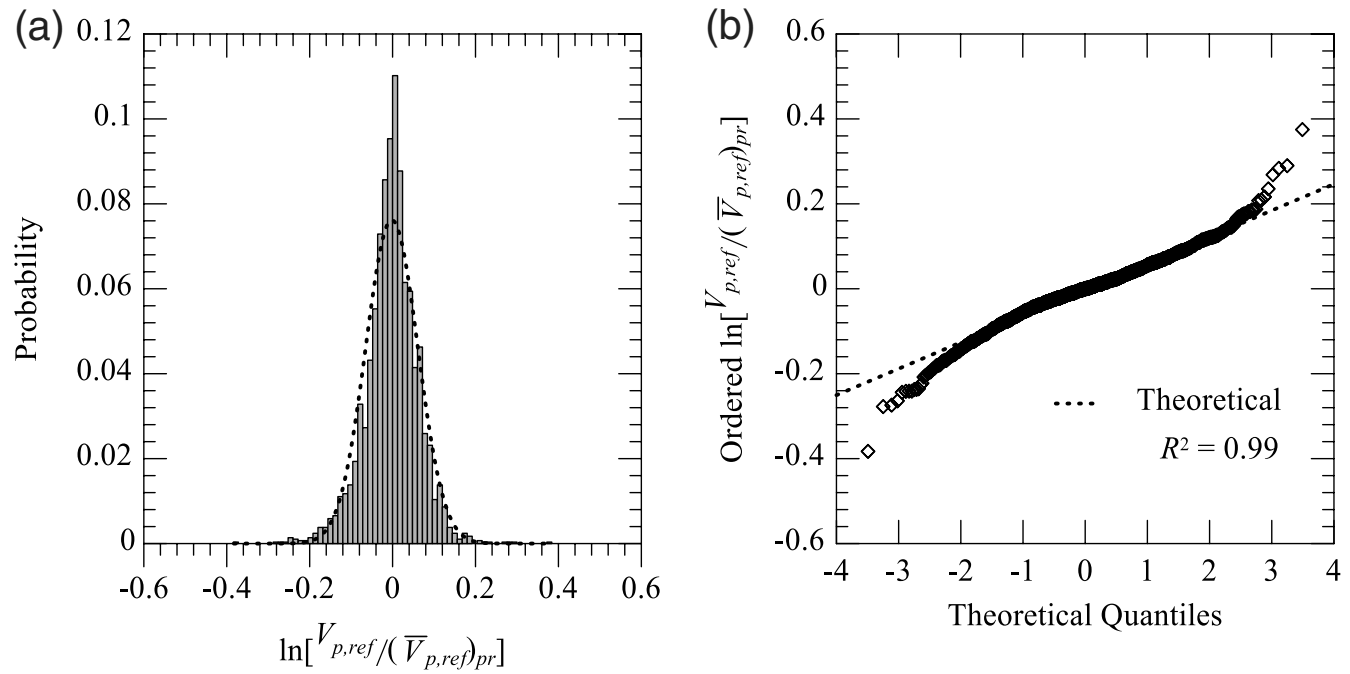

Figure 11. (a) Comparison of the within-profile $V_{P \text {,ref }}$ data to a lognormal distribution, (b) the ordered mean values versus theoretical quantiles (or $Q-Q$ plot). See Figure 8 for a description of the figure.

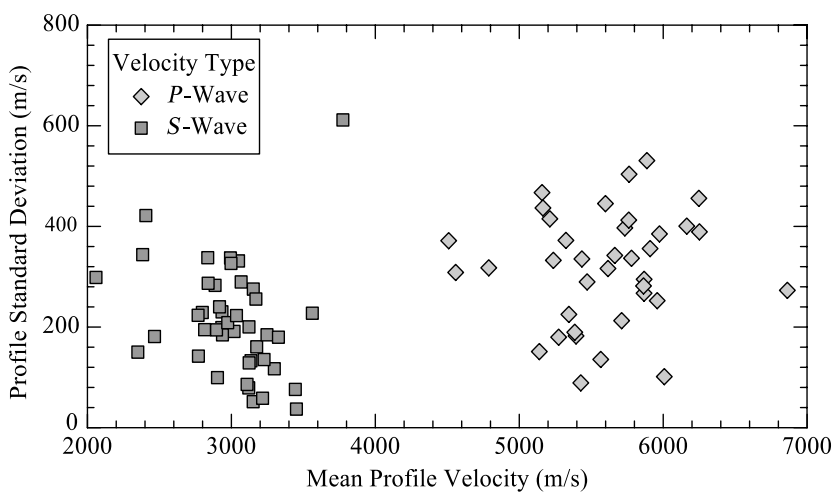

Figure 12. Influence of mean profile velocity on the withinprofile standard deviation.

This between-profile variability is evaluated from four sites with 8-12 profiles (i.e., Bell Bend NPP, Bellefonte NPP, V.C. Summer NPP, and William States Lee III NPP) as given in Table 3. Using the Shapiro-Wilk test and a confidence level

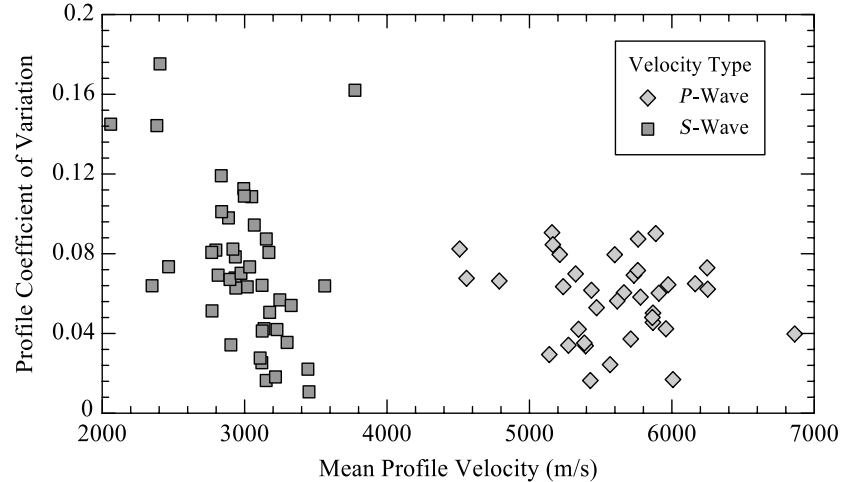

Figure 13. Influence of mean profile velocity on the variation of the within-profile coefficients of variation.

of 0.10, no data were rejected against normal and lognormal distributions, except for the William States Lee III NPP $S$-wave data being rejected for both distributions. The normal distribution is used based on results of the Shapiro-Wilk test

Table 3

Standard Deviation and Coefficient of Variation (COV) of Reference Rock Values from Sites with More than Seven Values

\begin{tabular}{llccc}
\hline Velocity Type & \multicolumn{1}{c}{ Site } & Count & Standard Deviation & COV \\
\hline$P$ wave & Bell Bend NPP* & 8 & 586 & 0.114 \\
& Bellefonte NPP & 8 & 98 & 0.017 \\
& V.C. Summer NPP & 8 & 227 & 0.041 \\
& William States Lee III NPP & 9 & 406 & 0.070 \\
& Mean & & 329 & 0.061 \\
\multirow{5}{*}{ wave } & Bell Bend NPP & 8 & 370 & 0.127 \\
& Bellefonte NPP & 8 & 99 & 0.033 \\
& V.C. Summer NPP & 8 & 118 & 0.037 \\
& William States Lee III NPP & 12 & 200 & 0.068 \\
& Mean & & 197 & 0.066 \\
\hline
\end{tabular}

*NPP, Nuclear Power Plant 

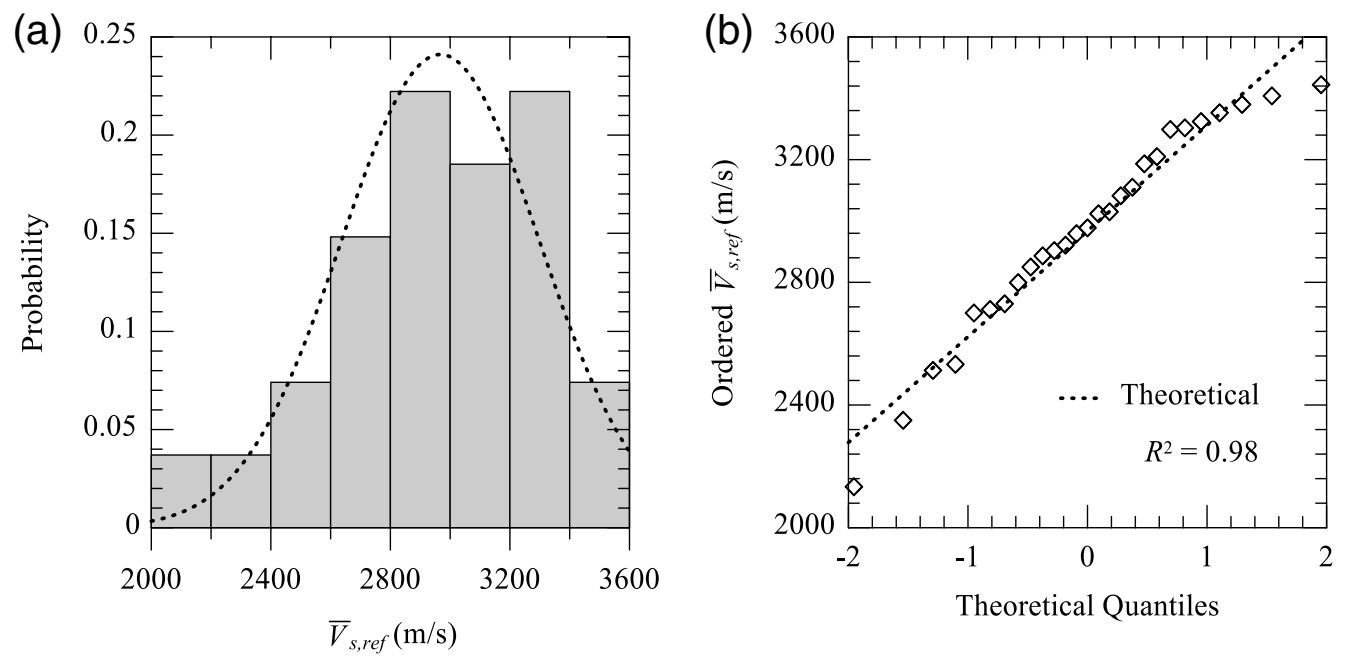

Figure 14. (a) Distribution of the mean reference $S$-wave velocity measurements at all sites, (b) the ordered mean values versus theoretical quantiles (or $Q-Q$ plot) by comparing with the shape of the distribution with the assumed normal distribution. Deviations from the 1to-1 line indicate deviations from the assumed distribution.
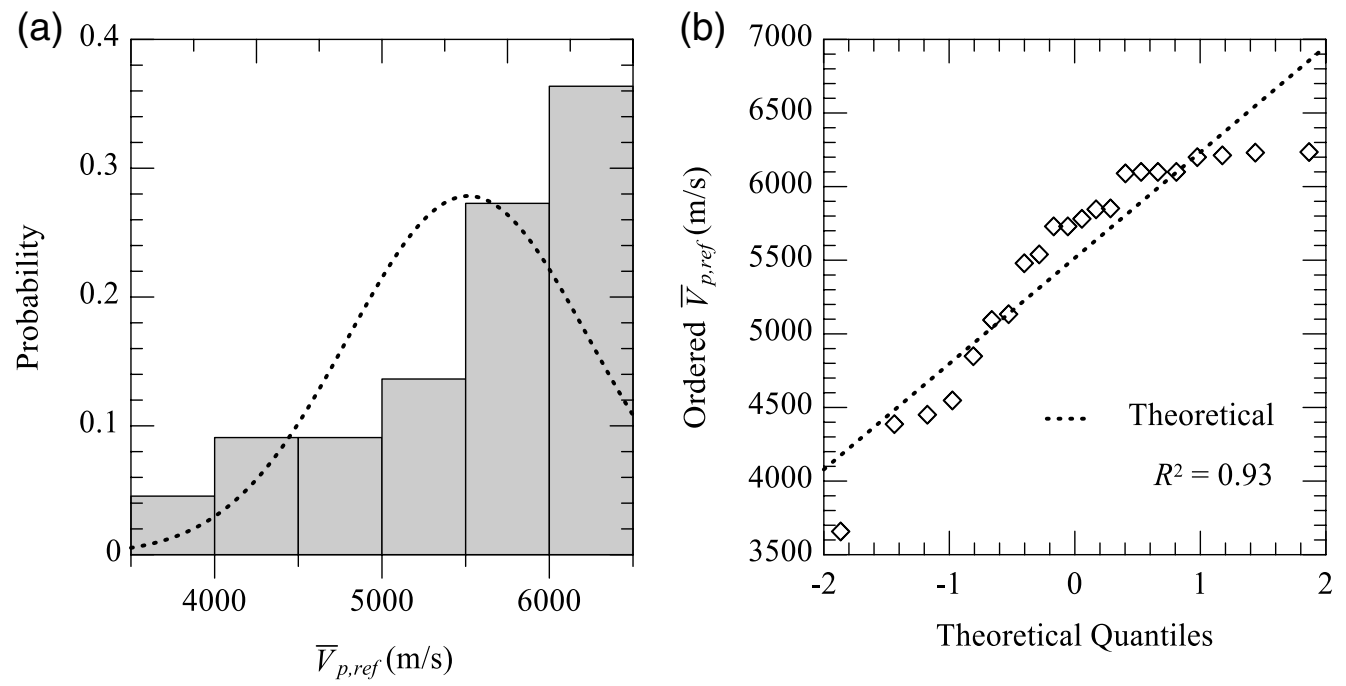

Figure 15. (a) Distribution of the mean reference $P$-wave velocity measurements at all sites, (b) the ordered mean values versus theoretical quantiles (or $Q-Q$ plot). See Figure 14 for a description of the figure.

and judgment. The between-profile COV range from 0.033 to 0.127 for $\mathrm{COV}_{V_{S}}^{\text {site } \text {,ref }}$ and 0.017 to 0.114 for $\mathrm{COV}_{V_{P} \text {,ref }}^{\text {site }}$ Given the similar range in COV and the relationship between $S$ - and $P$-wave velocities, a single coefficient variation of 0.063 is recommended for both $\mathrm{COV}_{V_{S} \text {,ref }}^{\text {site }}$ and $\operatorname{COV}_{V_{P} \text {,ref }}^{\text {site }}$, which is quite similar to $\mathrm{COV}_{\text {profile }}$ of 0.067 .

Regional Characteristics. Histograms of $\left(\bar{V}_{S, \text { ref }}\right)_{\text {site }}$ and $\left(\bar{V}_{P, \text { ref }}\right)_{\text {site }}$ are shown in Figures 14 and 15, respectively. The histograms of the $S$ - and $P$-wave velocities skew toward faster velocities. Using the reference $S$-wave velocity data, the Shapiro-Wilk test was used to test for normality. Using an alpha factor of 0.10 , the computed $p$ value of 0.30 does not reject assumed normal distribution for $\left(\bar{V}_{S, \text { ref }}\right)_{\text {site }}$, but the $p$ value of 0.006 does reject the assumed normal distribution for $\left(\bar{V}_{P, \text { ref }}\right)_{\text {site }}$. Considering site-to-site variability of mean reference velocities, a regional weighted mean is computed with weights taken as proportional to the reciprocal of the standard error, defined by the $\mathrm{COV}_{V_{S}}^{\text {site }}$,ef and $\mathrm{COV}_{V_{P} \text {,ref }}^{\text {site }}$ values divided by the square root of the number of profiles, to provide a maximum likelihood estimate of the regional mean (denoted as $\left(\bar{V}_{S, \text { ref }}\right)_{\text {reg }}$ and $\left.\left(\bar{V}_{P \text {,ref }}\right)_{\text {reg }}\right)$. For the four wellsampled sites, the standard deviations in Table 3 are used for weighting. For more sparsely sampled sites (having one to three profile means), the standard deviation is computed by assuming a mean site COV of 0.063 . Weighted standard deviations are computed (denoted as $\operatorname{COV}_{V_{S} \text {,ref }}^{\text {reg }}$ and $\mathrm{COV}_{V_{P} \text {,ref }}^{\text {reg }}$, which represent regional site-to-site variability of the mean velocity. Results for both weighted mean and standard deviation are given in Table 4. Combining site- 
to-site and between-profile standard deviations yields COV of 0.144 and 0.128 for $\operatorname{COV}_{V_{S} \text {,ref }}^{\text {reg }}$ and $\operatorname{COV}_{V_{p} \text {,ref }}^{\text {reg }}$, respectively. These mean values and their $95 \%$ confidence intervals are $\left(\bar{V}_{S, \text { ref }}\right)_{\text {reg }}=2951 \pm 831 \mathrm{~m} / \mathrm{s}$ (i.e., $\left.2120-3782 \mathrm{~m} / \mathrm{s}\right)$ and $\left(\bar{V}_{P, \text { ref }}\right)_{\text {reg }}=5517 \pm 1380 \mathrm{~m} / \mathrm{s}$ (i.e., $\left.4137-6897 \mathrm{~m} / \mathrm{s}\right)$.

We do not find evidence for regional dependence of the reference velocities, which are derived principally from three general geographic regions: (1) Atlantic coast, (2) continental interior, and (3) Appalachian Mountains. Our data do not provide reference velocities for the Gulf Coast region (details in Hashash et al., 2013). In that region, the depth to the CENA reference rock condition is much greater than other CENA regions due to several kilometers of overlying sediments. Therefore, a reference rock condition is not provided for the Gulf Coast. Our recommendation is to adopt a consistent reference rock condition for the entire CENA region, as given above, for application of the NGA-East GMPEs. As described in Stewart et al. (2013), practical applications involving softer site conditions will require a linear modification to a softer reference condition (such as $760 \mathrm{~m} / \mathrm{s}$ ) along with appropriate nonlinear site factors referenced to $760 \mathrm{~m} / \mathrm{s}$ (or similar).

Slowness, which is defined as the reciprocal of velocity, was considered as an alternate method for calculating the mean reference velocity. The regional weighted mean reference $S$-wave slowness was found to be $0.3450 \mathrm{~ms} / \mathrm{m}$ with a standard deviation of $4.3 \times 10^{-5} \mathrm{~ms} / \mathrm{m}$. The mean $S$-wave slowness corresponds to a $\left(\bar{V}_{S, \text { ref }}\right)_{\mathrm{pr}}$ of approximately $2900 \mathrm{~m} / \mathrm{s}$. The statistics computed using velocities, not slowness, is recommended because of the insignificant difference between these two numbers and the simplicity of directly computing the statistics from velocity.

Recommended Values. The mean regional reference velocities for CENA, with their $95 \%$ confidence intervals, were found from the data assembled in this study to be $\left(\bar{V}_{S, \text { ref }}\right)_{\text {reg }}=2951 \pm 831 \mathrm{~m} / \mathrm{s}$ (i.e., $\left.2120-3782 \mathrm{~m} / \mathrm{s}\right)$ and $\left(\bar{V}_{P, \text { ref }}\right)_{\text {reg }}=5517 \pm 1380 \mathrm{~m} / \mathrm{s}$ (i.e., $4137-6897 \mathrm{~m} / \mathrm{s}$ ). For application purposes, we recommend the use of mean values having no more than two significant digits, which give the following values:

$$
V_{S, \text { ref }}=3000 \mathrm{~m} / \mathrm{s} \quad \text { or } 9800 \mathrm{ft} / \mathrm{s}
$$

and

$$
V_{P, \text { ref }}=5500 \mathrm{~m} / \mathrm{s} \text { or } 18,000 \mathrm{ft} / \mathrm{s} \text {. }
$$

Note that the statistical nomenclature has been dropped for these recommendations, because they are interpreted (and slightly modified) from the formal statistics.

The data gathered in this study reveal substantial site-tosite variability of mean reference velocities. This is important for site-specific ground-motion studies, in which geotechnical and geophysical logging to depths corresponding to the reference conditions may be required by regulatory agencies. Given the aforementioned site-to-site variability, we do not advocate strict adherence to reaching the $V_{S \text {,ref }}$ and $V_{P \text {,ref }}$
Table 4

Standard Deviation and Coefficient of Variation (COV) of the Reference Rock Velocities Weighted by the Reciprocal of the Standard Deviation

\begin{tabular}{ccccc}
\hline & & \multicolumn{3}{c}{ Standard Deviation (COV) } \\
\cline { 3 - 5 } Velocity Type & Mean & Within Site* & Between Site & Total \\
\hline$P$ wave & 5517 & $348(0.063)$ & $612(0.111)$ & $704(0.128)$ \\
$S$ wave & 2951 & $186(0.063)$ & $381(0.129)$ & $424(0.144)$ \\
\hline
\end{tabular}

*The within-site standard deviation is estimated using a coefficient of variation of 0.063 .

values given above. Our principal recommendation is that the depth of exploration be sufficient enough that the reference condition, as defined earlier in this paper, is demonstrated by the data.

With that said, it is recognized that many applications require articulation of a specific reference velocity (or range). In application, the selected velocity range is more rationally defined from its impact on site amplification rather than by the width of confidence intervals. For this reason, we derive a velocity range based on its impact on site amplification. The amplification in a vertically propagating horizontally polarized $S$ wave between two layers is related to the mass density $(\rho)$ and velocity $(V)$ in the layers (Joyner et al., 1981) as

$$
A=\sqrt{\frac{\rho_{1} V_{1}}{\rho_{2} V_{2}} .}
$$

If the layers have the same mass densities, then the amplification across those two layers is equal to the square root of the velocity ratio (i.e., $\sqrt{V_{1} / V_{2}}$ ). An admittedly subjective limit on amplification change of 5\% is selected, which implies that for a given soil layer velocity, the range in reference rock velocity is $0.907-1.108$ of the central value. This corresponds to a computed range of $2700-3300 \mathrm{~m} / \mathrm{s}$ for $V_{S \text {,ref }}$ and 5000-6100 m/s for $V_{P \text {,ref. }}$ The range is somewhat smaller than the $95 \%$ confidence interval given above. The EPRI (1993) recommendation for $V_{S, \text { ref }}$ falls within this range, which means that prior seismic-hazard analyses for nuclear power plants utilizing this value are compatible with our recommendations. However, the $P$-wave reference velocity from EPRI (1993) of $V_{P, \text { ref }}=4900 \mathrm{~m} / \mathrm{s}$ falls outside the recommended range.

Based on the above reasoning, the recommended range of $V_{S, \text { ref }}$ is $2700-3300 \mathrm{~m} / \mathrm{s}(8900-10,800 \mathrm{ft} / \mathrm{s})$ and of $V_{P, \text { ref }}$ is $5000-6100 \mathrm{~m} / \mathrm{s}(16,400-20,000 \mathrm{ft} / \mathrm{s})$.

\section{Comparison with Laboratory Measurements}

Brant et al. (2012) conducted in situ and laboratory tests on metamorphic and igneous rock cores from the New York area. These tests are of interest because the cores are composed of competent, relatively unweathered bedrock that is generally compatible with the descriptions of reference rock in boring logs. 
The laboratory measurements by Brant et al. (2012) were conducted using the resonant frequency method with impulse excitation (ASTM International, 2008). No confinement was applied to the samples. The $118 S$-wave velocities from the laboratory measurements of rock cores ranged from 1520 to $4570 \mathrm{~m} / \mathrm{s}$ with a mean of $3050 \mathrm{~m} / \mathrm{s}$. For each laboratory test, an associated in situ velocity measurement is available from geophysical crosshole, downhole, or suspension logging methods. Brant et al. (2012) compared the lab and in situ velocity measurements and found the laboratory measurements provide an upper bound on the $S$-wave velocity of the in situ rock mass. This is due to the presence of joints and discontinuities in the rock mass which are not present in the cores due to both their small size and the need to test intact (as opposed to fractured) specimens. Although the direct use of laboratory measurements for the evaluation of reference rock velocities is not advocated, it is encouraging that the mean regional $S$-wave velocity of $\left(\bar{V}_{S, \text { ref }}\right)_{\text {reg }}=$ $2950 \mathrm{~m} / \mathrm{s}$ is very close to the rock core mean of $3050 \mathrm{~m} / \mathrm{s}$.

\section{Characteristics of the Velocity Profiles}

Poisson's Ratios. For each profile in reference rock, $\left(\bar{V}_{S, \text { ref }}\right)_{\mathrm{pr}}$ and $\left(\bar{V}_{P \text {,ref }}\right)_{\mathrm{pr}}$ are used to compute the mean profile Poisson's ratio, $\left(\bar{\nu}_{\text {ref }}\right)_{\text {pr }}$, as follows (Mavko et al., 2003):

$$
\left(\bar{\nu}_{\text {ref }}\right)_{\mathrm{pr}}=\frac{\left(\bar{V}_{P, \text { ref }}\right)_{\mathrm{pr}}^{2}-2\left(\bar{V}_{S, \text { ref }}\right)_{\mathrm{pr}}^{2}}{2\left(\bar{V}_{P, \text { ref }}\right)_{\mathrm{pr}}^{2}-2\left(\bar{V}_{S, \text { ref }}\right)_{\mathrm{pr}}^{2}} .
$$

The computed Poisson's ratios range from 0.24 to 0.33 with a mean of 0.28 , as shown in Figure 16 . The computed values fall within the range expected for intact rock presented by Gercek (2007). The mean value of 0.28 is similar to the assumed value of 0.25 used by EPRI (1993).

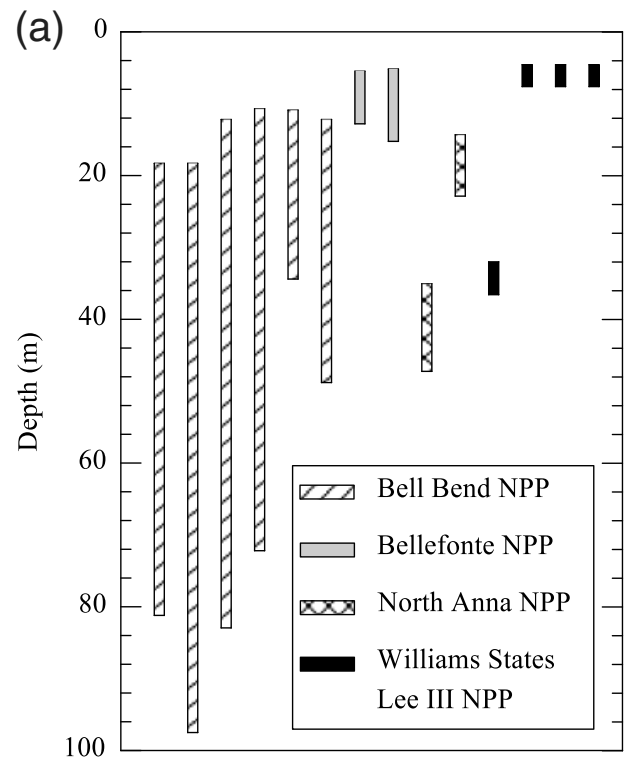

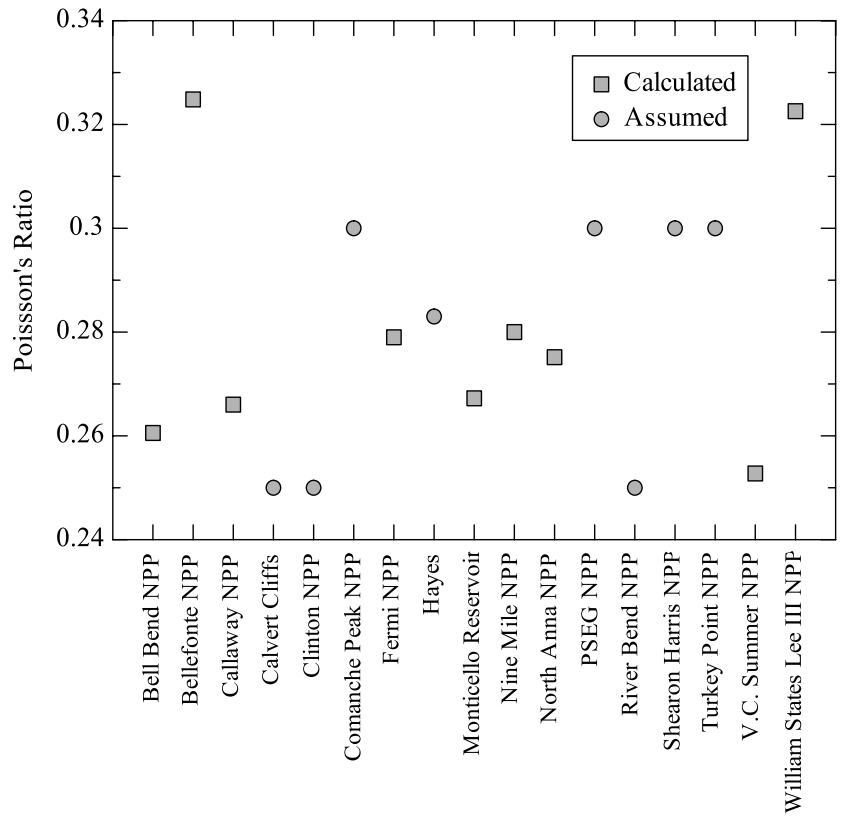

Figure 16. Poisson's ratio computed from mean reference velocity measurements, as well as reported assumed values. The mean $(\mu)$ and standard deviation $(\sigma)$ was computed to be 0.28 and 0.025 , respectively.

Weathered Zone. At the Bellefonte, North Anna, V.C. Summer, and William States Lee III sites, information regarding the transition from weathered rock to intact rock could be inferred from the velocity profiles and borehole geology. At the other sites, no weathering zone could be identified. The thickness and range in $S$-wave velocities associated with the identified weathered zones is shown in Figure 17. The top of the weathered zone occurs at depths ranging from 4.5 to $35 \mathrm{~m}$ with thicknesses varying from 3 to $83 \mathrm{~m}$. The velocity at the top of the weathered zone varies

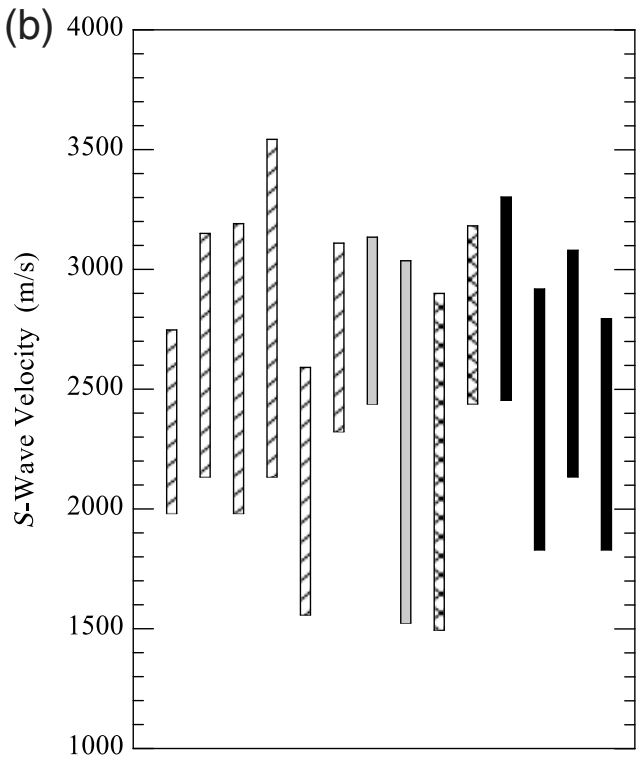

Figure 17. The range of (a) depths and (b) velocities observed in the identified weathered zones. 


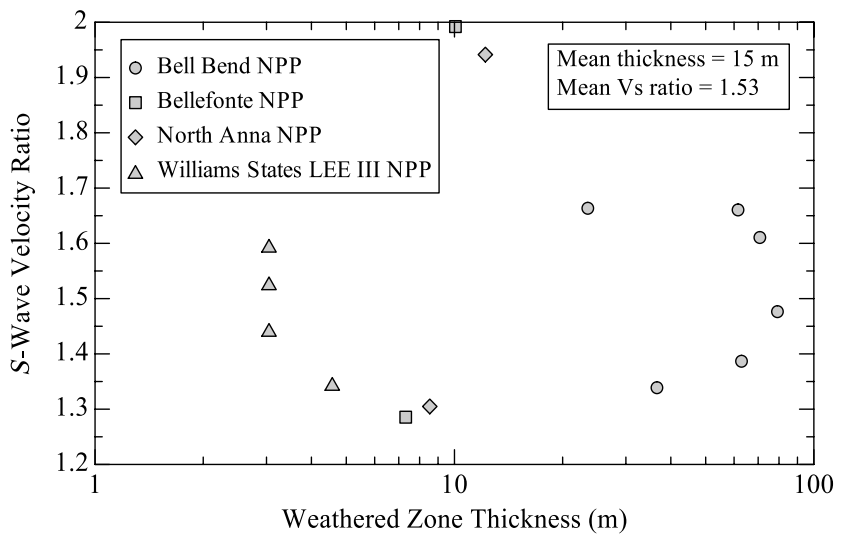

Figure 18. The relationship between weathered zone thickness and ratio of $S$-wave velocity at the top and base of the weathered zone. The geometric mean of the thickness is $15 \mathrm{~m}$ and the median $S$-wave velocity ratio is 1.53 .

from 1500 to $2450 \mathrm{~m} / \mathrm{s}$ and at the base of the weathered zone varies from 2590 to $3540 \mathrm{~m} / \mathrm{s}$. The ratio of the $S$-wave velocity of the intact rock to the weathered rock, referred to as $S$-wave velocity ratio, ranges from 1.3 to 2 (Fig. 18). The geometric mean of the thickness is $15 \mathrm{~m}$ and the $S$-wave velocity ratio is 1.53 .

Velocity Gradients. The velocity gradient is defined as the change in velocity with respect to depth $(d V / d z)$. It can be computed over a depth range and used as a parameter to assist in identifying reference rock conditions within a profile. Within the reference rock, the velocity gradient is computed for all profiles with at least four measurements spanning a depth range of at least $5 \mathrm{~m}$ by fitting a linear model through the data. There are 82 profiles with a sufficient amount of data to compute the velocity gradient. The reference velocity gradient ranges from $d V / d z=-64$ to $46(\mathrm{~m} / \mathrm{s}) / \mathrm{m}$ with a mean of $2(\mathrm{~m} / \mathrm{s}) / \mathrm{m}$ and standard deviation of $13(\mathrm{~m} / \mathrm{s}) / \mathrm{m}$.
The associated $95 \%$ confidence interval is -24 to $28(\mathrm{~m} / \mathrm{s}) / \mathrm{m}$. The velocity gradient within weathered zones is computed by change in velocity between the top and base of the zone divided by the thickness. Computed velocity gradients within weathered zones range from 10 to 635 (m/s)/m with a mean of $165(\mathrm{~m} / \mathrm{s}) / \mathrm{s}$. A comparison of the reference and weathered zone velocity gradients is shown in Figure 19. The magnitude of the velocity gradient within the weathered and reference zones do overlap for some sites. For a specific profile, the difference between the velocity gradient in the weathered rock and reference rock is always greater than zero, as shown in Figure 20, indicating a decrease in the velocity gradient as the profile transitions from the weathered zone into the reference velocity zone.

\section{Reference Rock Unit Weight}

In addition to the velocity and the site attenuation, the reference rock unit weight is a parameter required in site response analyses and seismological simulations. Boore and Joyner (1997) proposed a relationship between $V_{S}$ and density. A density of $2.75 \mathrm{gm} / \mathrm{cm}^{3}$, which corresponds to a unit weight of $27 \mathrm{kN} / \mathrm{m}^{3}$, is computed using $V_{S \text {,ref }}$. Brant et al. (2012) provide a relationship between intact $V_{S}$ or $V_{P}$ and unit weight based on measurements of velocity and unit weight conducted in the laboratory. Unit weights of 26.7 and $28.8 \mathrm{kN} / \mathrm{m}^{3}$ are computed from $V_{S \text {,ref }}$ and $V_{P \text {,ref }}$, respectively, using the Brant et al. (2012) relationship. A unit weight of $27 \mathrm{kN} / \mathrm{m}^{3}$ (or $172 \mathrm{pcf}$ ) is selected as a representative unit weight for the reference rock materials.

\section{Reference Site Attenuation (Kappa)}

The site attenuation parameter $\left(\kappa_{0}\right)$ characterizes the influence of the local subsurface geological structure on the high-frequency attenuation of ground motion. In stochastic
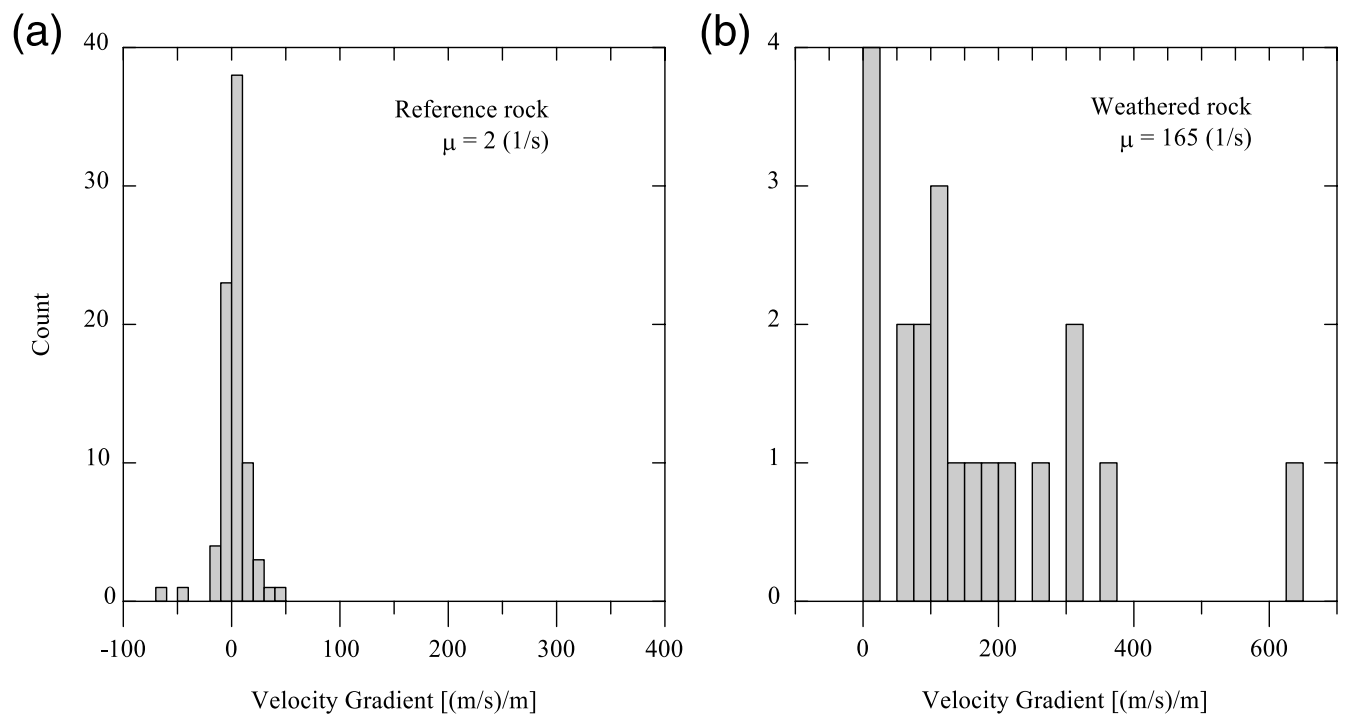

Figure 19. Velocity gradients within (a) the reference rock and (b) weathered zones. 


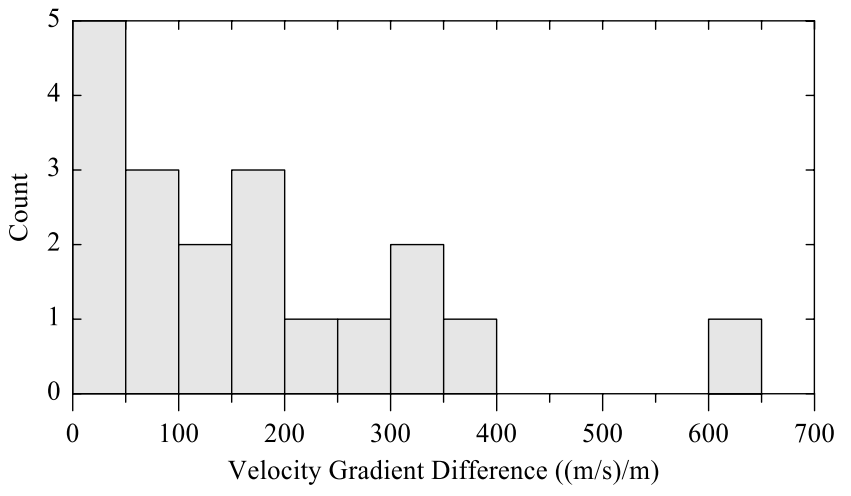

Figure 20. Difference between weathered and reference velocity zone velocity gradients.

ground-motion simulations (e.g., Boore, 2003), site attenuation is applied separately from anelastic crustal damping $(Q)$, which is considered a path effect. Accordingly, $\kappa_{0}$ is taken as independent of distance and is given a lower bound of zero. The site attenuation governs the high-frequency characteristics of the ground motion at site-source distances lower than about $50 \mathrm{~km}$, where crustal damping effects are small. More background on $\kappa_{0}$, the procedures used to derive it from data, and recommended values for various site conditions are given in Campbell (2009) and Campbell et al. (2013).

As described further in Campbell et al. (2013), we developed recommended values of reference site attenuation $\left(\kappa_{0, \text { ref }}\right)$ based on hard-rock estimates of $\kappa_{0}$, as well as published $\kappa_{0}-V_{S 30}$ relationships (in which $V_{S 30}$ is the time-averaged $S$-wave velocity in the top $30 \mathrm{~m}$ of a site). There are very limited numbers of available $\kappa_{0}$ estimates for CENA hard-rock sites, or for that matter, any hard-rock sites in stable continental regions throughout the world. In addition, it is not clear what type of probability distribution should be used to characterize uncertainty in $\kappa_{0}$ and whether this distribution should be different for the aleatory and epistemic components. We do not address what the median value of $\kappa_{0}$ and its uncertainty should be for the carbonate platform regions of CENA, which are common in the Midwest region of North America. One might expect site attenuation in this region to be greater than that for hard rock (e.g., Chandler et al., 2006).

Figure 21 shows mean values of hard-rock $\kappa_{0}$ in CENA from various sources in the literature, which range from 0.002 to 0.009 s (Atkinson, 1984, 1996; Toro and McGuire, 1987; Silva et al., 1988; Silva and Darragh, 1995; Chapman et al., 2003; Atkinson and Boore, 2006; Campbell, 2009). Also shown are mean $\kappa_{0}$ values derived from WNA recordings on hard rock, which range from 0.0003 to $0.01 \mathrm{~s}$ (Hough et al., 1988; Anderson, 1991; Silva and Darragh, 1995; Atkinson, 1996; Campbell, 2009). Figure 21 also shows various $\kappa_{0}-V_{S 30}$ relationships from the literature. The plotted relationships are Silva et al. (1999) for northern California, Chandler et al. (2006) for global active and stable tectonic regimes, Edwards et al. (2011) as modified by Edwards (2012) for Switzerland (using three relationships between $\kappa_{0}$

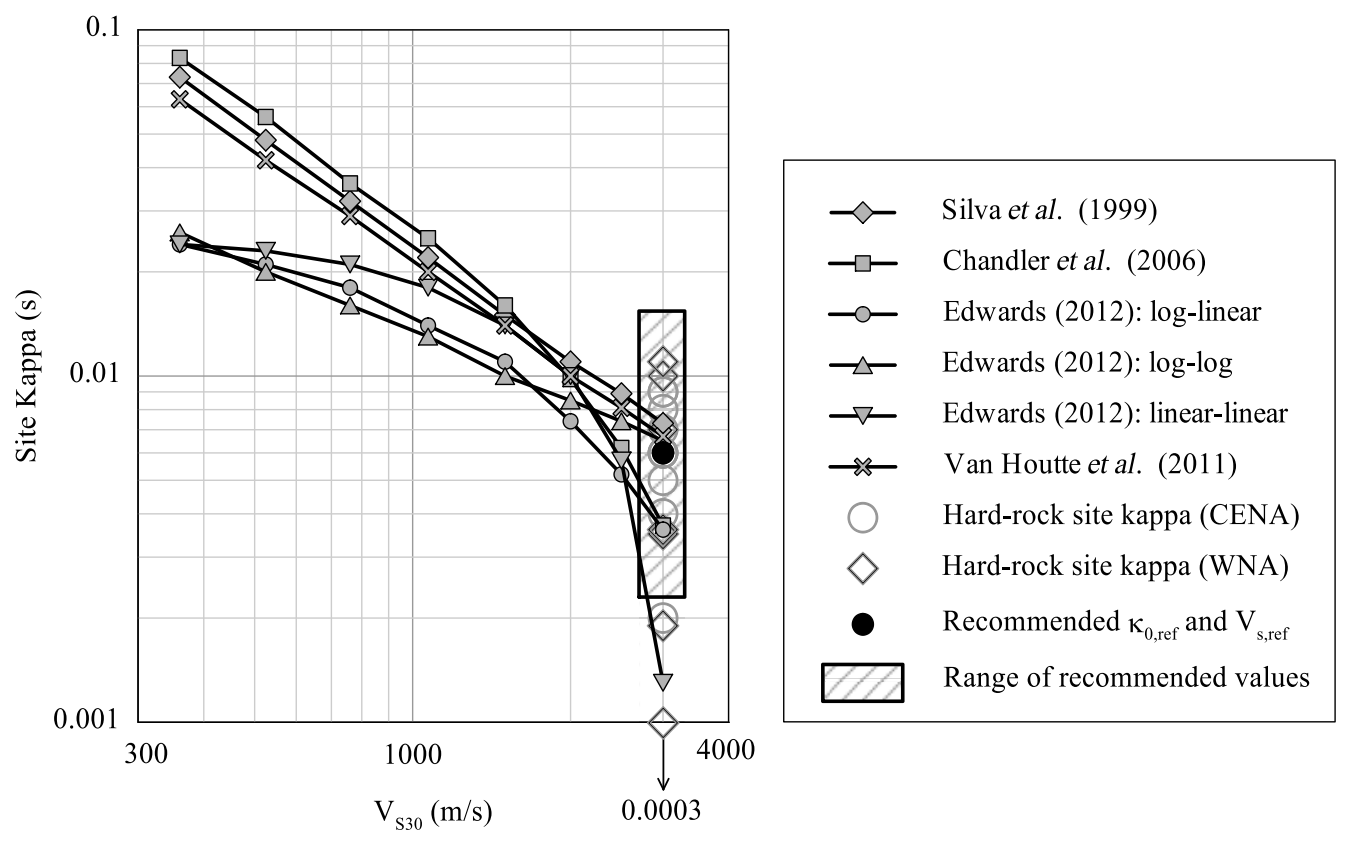

Figure 21. A comparison of estimates of site kappa $\left(\kappa_{0}\right)$ from selected $\kappa_{0}-V_{S 30}$ relationships with the reference site kappa value $\left(\kappa_{0, \text { ref }}\right)$ recommended in this study for the reference rock $S$-wave velocity $\left(V_{S, \text { ref }}\right)$. The hard-rock site kappa values for CENA (Atkinson, 1984, 1996; Toro and McGuire, 1987; Silva et al., 1988; Silva and Darragh, 1995; Chapman et al., 2003; Atkinson and Boore, 2006; Campbell, 2009) and WNA (Hough et al., 1988; Anderson, 1991; Silva and Darragh, 1995; Atkinson, 1996; Campbell, 2009) are shown. The shaded box represents the 95th percentile (plus and minus two standard deviations) of the total distribution of the reference rock site kappa $\left(\kappa_{0, \text { ref }}\right)$ that includes epistemic uncertainty in source, path, and site amplification effects, as well as the range of recommended values of $V_{S, \text { ref }}$ $(3000 \pm 300 \mathrm{~m} / \mathrm{s})$. 
Table 5

Recommended Distribution of Reference Rock Site Kappa in Central and Eastern North America

\begin{tabular}{lc}
\hline \multicolumn{1}{c}{ Distribution Parameter } & Value \\
\hline Type of distribution & Lognormal \\
Median, $\kappa_{0, \text { ref }}(\mathrm{s})$ & 0.006 \\
Aleatory standard deviation, $\phi_{\ln \kappa_{0, \text { ref }}}(\mathrm{s})$ & 0.43 \\
Epistemic standard deviation, $\varepsilon_{\ln \kappa_{0, \text { ref }}}(\mathrm{s})$ & 0.12 \\
$\quad$ Excluding source, path, and site uncertainty & 0.20 \\
$\quad$ Including source, path, and site uncertainty & \\
Total standard deviation, & \\
$\quad \sigma_{\ln \kappa_{0, \text { ref }}}=\sqrt{\phi_{\ln \kappa_{0, \text { ref }}^{2}}^{2}+\varepsilon_{\ln \kappa_{0, \text { ref }}}^{2}}$ & 0.45 \\
$\quad$ Excluding source, path, and site uncertainty & 0.47 \\
$\quad$ Including source, path, and site uncertainty & \\
Coefficient of variation $\left(\mathrm{COV}=\sqrt{\left.\text { exp }\left(\sigma^{2}\right)-1\right)}\right.$ & 0.45 \\
$\quad$ Aleatory variability & \\
Epistemic uncertainty & 0.47 \\
$\quad$ Excluding source, path, and site uncertainty & 0.50 \\
$\quad$ Including source, path, and site uncertainty & \\
95th confidence interval; $\pm 2 \sigma$ range $(\mathrm{s})$ & $0.0024-0.0148$ \\
$\quad$ Excluding source, path, and site uncertainty & $0.0023-0.0154$ \\
Including source, path, and site uncertainty & \\
\hline
\end{tabular}

and $V_{S 30}: \log$-linear, log-log, and linear-linear), and Van Houtte et al. (2011) for Japan, California, and Taiwan. The $\kappa_{0}$ values of the model predictions range from 0.0013 to $0.007 \mathrm{~s}$ at $V_{S 30}=3000 \mathrm{~m} / \mathrm{s}$, with the Swiss models being lowest. The non-Swiss models fall in the range of 0.004$0.007 \mathrm{~s}$ at $V_{S 30}=3000 \mathrm{~m} / \mathrm{s}$, which is consistent with the CENA hard-rock values.

As described in Campbell et al. (2013), we recommend the reference rock site attenuation $\left(\kappa_{0, \text { ref }}\right)$ be represented by a lognormal distribution with a median value $\left(\bar{\kappa}_{0, \text { ref }}\right)$ of $0.006 \mathrm{~s}$ (Table 5), which affirms the earlier results through the review of various studies. A lognormal distribution for $\kappa_{0, \text { ref }}$ was chosen because (1) it has precedence in the literature and (2) it does not allow for negative values, which are nonphysical. An aleatory natural $\log$ standard deviation $\phi_{\ln \kappa_{0 \text { ref }}}$ of 0.43 is recommended based on the range of CENA hard-rock $\kappa_{0}$, as well as reports by Schneider et al. (1993) and Silva and Darragh (1995). Ground-motion simulations employing these $\kappa_{0}$ values should consider epistemic uncertainties. Such epistemic uncertainties can be represented with a lognormal distribution with a standard deviation of 0.12 when the uncertainty of seismological and geophysical parameters is incorporated into the simulations (Schneider et al., 1993; Silva and Darragh, 1995). Alternatively, when the uncertainty in input parameters is not incorporated into the simulations, a standard deviation of 0.20 is recommended based on Edwards et al. (2011).

\section{Summary and Conclusions}

The notion of reference rock is a convenient means by which a standard site condition can be used for groundmotion prediction with GMPEs or simulations. Under this approach, reference site ground motions are modified on a site-specific basis given the geologic conditions present at the site above something akin to a reference rock layer. As such, the definition of reference rock is germane both to the development of ground-motion prediction tools and site amplification factors. We have developed recommendations for defining reference rock through a systematic review of available data from the CENA region. Reference rock is defined on the basis of $S$ - and $P$-wave velocities, site attenuation $\left(\kappa_{0}\right)$, and unit weight.

The prior definition of reference rock velocities in CENA was based mostly on indirect large-scale (i.e., on the order of kilometers) crustal $P$-wave velocity inversions and engineering judgment. In this study, we have developed recommended reference $S$ - and $P$-wave velocities based on systematic analysis of local-scale (i.e., order of $10 \mathrm{~s}$ of meters) measurements. A dataset was developed based on values reported in unpublished site investigation reports from nuclear power plants and the open literature. We analyzed these data to develop criteria to assess the presence of the reference rock site condition, which is based on the seismic velocities and their gradient with respect to depth. We apply the criteria to the available profiles from which we recommend $S$ - and $P$-wave velocities of 3000 and $5500 \mathrm{~m} / \mathrm{s}$, respectively. We recommend for practical application using a range of reference velocities, which we have developed based on a $\pm 5 \%$ change in amplification using quarter-wavelength theory. The corresponding ranges for $S$ - and $P$-wave velocities are $2700-3300 \mathrm{~m} / \mathrm{s}$ and $5000-6100 \mathrm{~m} / \mathrm{s}$, respectively. The widely used EPRI recommendation for $V_{S}$ velocity falls within the range identified in this study; however, the recommended $V_{P}$ velocity falls outside the identified range. We do not find evidence for regional dependence of the reference velocities, which are derived principally from three general geographic regions: (1) Atlantic coast, (2) continental interior, and (3) Appalachian Mountains. Our data do not provide reference velocities for the Gulf Coast region.

We provide Poisson's ratio and unit weight of reference rock and characteristics of weathered zone, based on measurements. To facilitate stochastic ground-motion simulations, we have also compiled the reference site attenuation $\left(\kappa_{0, \text { ref }}\right)$ based on both published values within the study region and relationships between $\kappa_{0}$ and $V_{S 30}$ for other regions. A median value of $0.006 \mathrm{~s}$ is recommended. We also provided recommended distribution of $\kappa_{0, \text { ref }}$ assuming a lognormal distribution.

\section{Data and Resources}

This study relied on measurements by others listed in the References. The majority of the site-specific velocity profiles in the CENA region were collected from combined license applications for projected new nuclear power plants. These applications can be found in the United States NRC website (http://www.nrc.gov/reactors/new-reactors/col.html, last accessed February 2013). The site characterization can be found in section 2.5 of the license application. 


\section{Acknowledgments}

This study was partially sponsored by the Pacific Earthquake Engineering Research Center (PEER) as part of Next Generation Attenuation Relationships for Central and Eastern North America (NGA-East). This project was funded by the U.S. Nuclear Regulatory Commission (NRC), the U.S. Department of Energy (DOE), and the Electric Power Research Institute (EPRI), with the participation of the United States Geological Survey (USGS). Any opinions, findings, and conclusions or recommendations expressed in this material are those of the authors and do not necessarily reflect those of the organizations listed above.

This project would not have been possible without the support from the following individuals and companies. We thank Farhang Ostadan and Tarek Elkhoraibi of Bechtel, and Jeff Bachuber and Michael Gray of Fugro Consultants for providing digital velocity profiles for a number of nuclear power plant applications. We thank Richard Rivera-Lugo of the United States NRC for assisting with navigation of regulatory documents and license applications. We thank Michael Musgrove and Khatereh Khodaverdi for selecting reference rock velocity profiles. Finally, we thank Ataya Eltibi and Paul Khauli, who digitized velocity profiles for this project.

\section{References}

Anderson, J. G. (1991). A preliminary descriptive model for the distance dependence of the spectral decay parameter in southern California, Bull. Seismol. Soc. Am. 81, no. 6, 2186-2193.

Anderson, J. G., and S. E. Hough (1984). A model for the shape of the Fourier amplitude spectrum of acceleration at high frequencies, Bull. Seismol. Soc. Am. 74, no. 5, 1969-1993.

Andrus, R. D., C. D. Fairbanks, J. Zhang, W. M. Camp, T. J. Casey, T. J. Cleary, and W. B. Wright (2006). Shear-wave velocity and seismic response of near-surface sediments in Charleston, South Carolina, Bull. Seismol. Soc. Am. 96, no. 5, 1897-1914.

ASTM International (2008). ASTM D2845-08 Standard Test Method for Laboratory Determination of Pulse Velocities and Ultrasonic Elastic Constants of Rock, West Conshohocken, Pennsylvania.

Atkinson, G. M. (1984). Attenuation of strong ground motion in Canada from a random vibrations approach, Bull. Seismol. Soc. Am. 74, no. 6, 2629-2653.

Atkinson, G. M. (1996). The high-frequency shape of the source spectrum for earthquakes in eastern and western Canada, Bull. Seismol. Soc. Am. 86, no. 1A, 106-112.

Atkinson, G., and D. Boore (2006). Earthquake ground-motion prediction equations for eastern North America, Bull. Seismol. Soc. Am. 96, no. 6, 2181-2205.

Beresnev, I. A., and G. M. Atkinson (1997). Shear-wave velocity survey of seismographic sites in eastern Canada: Calibration of empirical regression method of estimating site response, Seismol. Res. Lett. 68, no. 6, 981-987.

Boore, D. M. (2003). Prediction of ground motion using the stochastic method, Pure Appl. Geophys. 160, 635-676.

Boore, D. M., and W. B. Joyner (1997). Site amplifications for generic rock sites, Bull. Seismol. Soc. Am. 87, no. 2, 327-341.

Brant, L. C., S. Nikolaou, and C. Moss (2012). Resonant frequency testing of New York City rock types, in Symposium on Dynamic Testing of Soil and Rock: Field and Laboratory, San Diego, California, 28-29 June 2012.

Budnitz, R. J., G. Apostolakis, D. M. Boore, L. S. Cluff, K. J. Coppersmith, C. A. Cornell, and P. A. Morris (1997). Recommendations for probabilistic seismic hazard analysis: Guidance on uncertainty and use of experts, NUREG/CR-6372, U.S. Nuclear Regulatory Commission, Washington, D.C.

Campbell, K. W. (2003). Prediction of strong ground motion using the hybrid empirical method and its use in the development of groundmotion (attenuation) relations in eastern North America, Bull. Seismol. Soc. Am. 93, no. 3, 1012-1033.
Campbell, K. W. (2009). Estimates of shear-wave $Q$ and $\kappa_{0}$ for unconsolidated and semiconsolidated sediments in Eastern North America, Bull. Seismol. Soc. Am. 99, no. 4, 2365-2392.

Campbell, K. W., Y. M. A. Hashash, B. Kim, A. R. Kottke, E. M. Rathje, W. W. Silva, and J. P. Stewart (2013). Reference rock site condition for Central and Eastern North America Part II-Attenuation (Kappa) definition, Pacific Earthquake Engineering Research Center, NGA-East.

Chandler, A. M., N. T. K. Lam, and H. H. Tsang (2006). Near-surface attenuation modelling based on rock shear-wave velocity profile, Soil. Dynam. Earthq. Eng. 26, no. 11, 1004-1014.

Chapman, M. C., P. Talwani, and R. C. Cannon (2003). Ground-motion attenuation in the Atlantic Coastal Plain near Charleston, South Carolina, Bull. Seismol. Soc. Am. 93, no. 3, 998-1011.

Chulick, G. S., and W. D. Mooney (2002). Seismic structure of the crust and uppermost mantle of north America and adjacent oceanic basins: A synthesis, Bull. Seismol. Soc. Am. 92, no. 6, 2478-2492.

Dames \& Moore (1974). Site parameter study: Gassar seismic design for General Atomic Company, Report No. 2395-001-02, San Franciso, California.

Daniels, J. J., G. R. Olhoeft, and J. H. Scott (1983). Interpretation of core and well log physical property data from drill hole UPH-3, Stephenson County, Illinois (Illinois Deep Hole Project, USA), J. Geophys. Res. 88, no. B9, 7346-7354.

Dorman, J., and R. Smalley (1994). Low-frequency seismic surface waves in the upper Mississippi embayment, Seismol. Res. Lett. 65, no. 2, 137-148.

Edwards, B. (2012). Site specific kappa, Rept. No. SED/PRP/R/035b/ 20120410, Swiss Federal Institute of Technology, Zurich, Switzerland.

Edwards, B., D. Fäh, and D. Giardini (2011). Attenuation of seismic shear wave energy in Switzerland, Geophys. J. Int. 185, no. 2, 967-984.

Electric Power Research Institute (EPRI) (1993). Guidelines for determining design basis ground motions, Report No. TR-102293, Palo Alto, California, http://www.epri.com/abstracts/Pages/ProductAbstract.aspx? ProductId=TR-102293-V1 (last accessed September 2013).

Gercek, H. (2007). Poisson's ratio values for rocks, Int. J. Rock. Mech. Min. Sci. 44, no. 1, 1-13.

Grubbs, F. E. (1969). Procedures for detecting outlying observations in samples, Technometrics 11, no. 1, 1.

Hashash, Y. M. A., A. R. Kottke, J. P. Stewart, K. W. Campbell, B. Kim, E. M. Rathje, W. W. Silva, S. Nikolaou, and C. Moss (2013). Reference rock site condition for Central and Eastern North America Part IVelocity definition, Pacific Earthquake Engineering Research Center, NGA-East.

Hough, S. E., J. G. Anderson, J. Brune, F. Vernon III, J. Berger, J. Fletcher, L. Haar, T. Hanks, and L. Baker (1988). Attenuation near Anza, California, Bull. Seismol. Soc. Am. 78, no. 2, 672-691.

Joyner, W. B., R. E. Warrick, and T. E. Fumal (1981). The effect of Quaternary alluvium on strong ground motion in the Coyote Lake, California, earthquake of 1979, Bull. Seismol. Soc. Am. 71, no. 4, 1333-1349.

Kafka, A. L., and J. W. Skehan (1990). Major geological features and lateral variation of crustal structure in southern New England, Tectonophysics 178, nos. 2/4, 183-192.

Kammerer, A. M., and J. P. Ake (2012). Practical implementation guidelines for SSHAC Level 3 and 4 hazard studies, NUREG-2117, U.S. Nuclear Regulatory Commission, Washington, D.C.

Luetgert, J. H., H. M. Benz, and S. Madabhushi (1994). Crustal structure beneath the Atlantic coastal plain of South Carolina, Seismol. Res. Lett. 65, no. 2, 180-191.

Mavko, G., T. Mukerji, and J. Dvorkin (2003). The Rock Physics Handbook, Cambridge University Press, Cambridge, United Kingdom, 329 pp.

Moos, D., and M. D. Zoback (1983). In situ studies of velocity in fractured crystalline rocks, J. Geophys. Res. 88, no. B3, 2345-2358.

Motazedian, D., J. A. Hunter, A. Pugin, and H. Crow (2011). Development of a $V_{S 30}$ (NEHRP) map for the city of Ottawa, Ontario, Canada, Can. Geotech. J. 48, no. 3, 458-472.

Nuclear Regulatory Commission (NRC) (2007). A performance-based approach to define the site-specific earthquake ground motion, United 
States Nuclear Regulatory Commission (NRC), Regulatory Guide 1.208, Washington, D.C.

Pezeshk, S., A. Zandieh, and B. Tavakoli (2011). Hybrid empirical groundmotion prediction equations for Eastern North America using NGA models and updated seismological parameters, Bull. Seismol. Soc. Am. 101, no. 4, 1859-1870.

Roblee, C. J., W. J. Suva, G. R. Toro, and N. Abrahamson (1996). Variability in site-specific seismic ground-motion design predictions, Geotechnical Special Publication (58 II): X24-1133.

Schneider, J. F., W. J. Silva, and C. Stark (1993). Ground motion model for the 1989 M 6.9 Loma Prieta earthquake including effects of source, path, and site, Earthq. Spectra 9, no. 2, 251-287.

Shapiro, S. S., and M. B. Wilk (1965). An analysis of variance test for normality (complete samples), Biometrika 52, nos. 3/4, 591-611.

Silva, W. J., and R. Darragh (1995). Engineering Characterization of Earthquake Strong Ground Motion Recorded at Rock Sites, Electric Power Research Institute, Palo Alto, California.

Silva, W., R. Darragh, N. Gregor, G. Martin, N. Abrahamson, and C. Kircher (1999). Reassessment of site coefficients and near-fault factors for Building Code Provisions, NEHRP External Research Program, Final Technical Report, U.S. Geological Survey Award No. 98HQGR1010.

Silva, W. J., R. B. Darragh, R. K. Green, and F. T. Turcott (1988). Spectral characteristics of small magnitude earthquakes with application to western and eastern North American tectonic environments, Report to U.S. Army Corps of Engineers Waterways Experiment Station, Vicksburg, Mississippi.

Stewart, J. P., J. Douglas, M. Javanbarg, Y. Bozorgnia, N. A. Abrahamson, D. M. Boore, K. W. Campbell, E. Delavaud, M. Erdikand, and P. J. Stafford (2013). Selection of ground motion prediction equations for the Global Earthquake Model, Earthq. Spectra, doi: 10.1193/ 013013EQS017M.

Toro, G. R., and R. K. McGuire (1987). An investigation into earthquake ground motion characteristics in eastern North America, Bull. Seismol. Soc. Am. 77, no. 2, 468-489.

Toro, G. R., N. A. Abrahamson, and J. F. Schneider (1997). Model of strong ground motions from earthquakes in central and eastern North America: Best estimates and uncertainties, Seismol. Res. Lett. 68 , no. $1,41-57$.

UniStar Nuclear Services LLC (2010). Bell Bend Nuclear Power Plant, Combined License Application, Part 2: Final Safety Analysis Report, Revision 2, http://www.nrc.gov/reactors/new-reactors/col/bell-bend/ documents.html (last accessed February 2013).

U.S. Nuclear Regulatory Commission (2013). Combined License Applications for New Reactors, http://www.nrc.gov/reactors/new-reactors/col .html (last accessed February 2013).

Van Houtte, C., S. Drouet, and F. Cotton (2011). Analysis of the origins of $\kappa$ (kappa) to compute hard rock to rock adjustment factors for GMPEs, Bull. Seismol. Soc. Am. 101, no. 6, 2926-2941.

Worthing, A. G., and J. Geffner (1943). Treatment of Experimental Data, John Wiley and Sons, Inc., New York, 342 pp.

Department of Civil and Environmental Engineering

University of Illinois at Urbana-Champaign

2230c Newmark Civil Engineering Laboratory

205 N. Mathews Avenue

Urbana, Illinois 61801

hashash@illinois.edu

(Y.M.A.H.)
Bechtel National, Inc.

50 Beale Street, 15/D22

San Francisco, California 94105-1895

akottke@ bechtel.com

(A.R.K.)

Civil and Environmental Engineering Department

University of California

5731 Boelter Hall

Los Angeles, California 90095

jstewart@seas.ucla.edu

(J.P.S.)

EQECAT, Inc.

1030 NW 161st Place

Beaverton, Oregon 97006

kcampbell@eqecat.com

(K.W.C.)

Risk Management Solutions, Inc

7575 Gateway Boulevard

Newark, California 94560

Byungmin.Kim@rms.com

(B.K.)

Mueser Rutledge Consulting Engineers

225 West 34th Street

New York, New York 10122

cmoss@mrce.com

snikolaou@mrce.com

(C.M., S.N.)

Department of Civil, Architectural, and Environmental Engineering University of Texas at Austin

301 E. Dean Keeton Street, STOP C1792

Austin, Texas 78712

e.rathje@mail.utexas.edu

(E.M.R.)

Pacific Engineering and Analysis

311 Pomona Avenue

El Cerrito, California 94530

pacificengineering@juno.com

(W.J.S.)
Manuscript received 17 May 2013; Published Online 25 March 2014 